\title{
Extrinsic KRAS signaling shapes the pancreatic microenvironment through fibroblast reprogramming.
}

Ashley Velez-Delgado ${ }^{1}$, Katelyn L. Donahue ${ }^{2}$, Kristee L. Brown ${ }^{3}$, Wenting Dư ${ }^{3}$, Valerie Irizarry-Negron ${ }^{3}$,

Rosa E. Menjivar ${ }^{4}$, Emily L. Lasse Opsahl ${ }^{2}$, Nina G. Steele ${ }^{1}$, Stephanie The ${ }^{5 \#, ~ J e n n y ~ L a z a r u s ~}{ }^{3, \# \#, ~ V e e r i n ~}$ R. Sirihorachai ${ }^{2}$, Wei Yan ${ }^{3}$, Samantha B. Kemp ${ }^{6}$, Samuel A. Kerk², Murali Bollampally ${ }^{7}$, Fatima Lima ${ }^{3}$, Costas A. Lyssiotis $2,8,9,10$, Arvind Rao 2,5,9,11,12, Howard C. Crawford 2,8,9,10\#\#, Filip Bednar 3,9 , Timothy L. Frankel $^{3,9,}$ Yaqing Zhang ${ }^{3,9^{*}}$ and Marina Pasca di Magliano ${ }^{1,2,3,4,9^{*}}$

${ }^{1}$ Department of Cell and Developmental Biology; ${ }^{2}$ Cancer Biology Program; ${ }^{3}$ Department of Surgery, ${ }^{4}$ Cellular and Molecular Biology Program; ${ }^{5}$ Department of Computational Medicine and Bioinformatics; ${ }^{6}$ Molecular and Cellular Pathology Program; ${ }^{7}$ Life Sciences and Arts college; ${ }^{8}$ Department of Molecular and Integrative Physiology; ${ }^{9}$ Rogel Cancer Center; ${ }^{10}$ Department of Internal Medicine, Division of Gastroenterology and Hepatology; ${ }^{11}$ Michigan Institute of Data Science (MIDAS); ${ }^{12}$ Department of Radiation Oncology

University of Michigan, Ann Arbor, MI 48109 USA

${ }^{\#}$ current affiliation: Cancer Data Science Shared Resource, University of Michigan, Ann Arbor, MI 48109 USA

\#\#current affiliation: Lazarus Medical Corporation, Stonyford, CA 95979 USA.

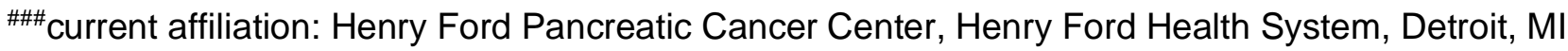
48202, USA.

${ }^{*}$ Corresponding authors

Marina Pasca di Magliano

Email: marinapa@umich.edu

Mail: Rogel Cancer Center Rm. 6306

1500 E Medical Center Dr. Ann Arbor, MI 48109

Tel: 7349369083 


\section{Yaqing Zhang}

\section{Email: yaqingzh@umich.edu}

Mail: Rogel Cancer Center Rm. 6110

1500 E Medical Center Dr. Ann Arbor, MI 48109

Tel: 7347633950

Correspondence: marinapa@umich.edu 


\section{ABSTRACT}

Oncogenic KRAS is the hallmark mutation of human pancreatic cancer and a driver of tumorigenesis in genetically engineered mouse models of the disease. While the tumor cell-intrinsic effects of oncogenic Kras expression have been widely studied, its role in regulating the extensive pancreatic tumor microenvironment is less understood. Using a genetically engineered mouse model of inducible and reversible oncogenic Kras expression and a combination of approaches that include mass cytometry and single cell RNA sequencing, we have discovered that non-cell autonomous (i.e., extrinsic) oncogenic KRAS signaling reprograms pancreatic fibroblasts, activating an inflammatory gene expression program. As a result, fibroblasts become a hub of extracellular signaling, mediating the polarization and function of pro-tumorigenic myeloid cells while also preventing tissue repair. Our study provides fundamental new knowledge on the mechanisms underlying the formation of the fibroinflammatory stroma in pancreatic cancer and highlights stromal pathways with the potential to be exploited therapeutically.

KEYWORDS: pancreatic cancer, KRAS, transformation, fibroblasts, macrophages, cellular plasticity 


\section{INTRODUCTION}

Pancreatic ductal adenocarcinoma (PDA) is the third leading cause of cancer-related death in the United States and is counted among the most lethal malignancies, with an expected 5-year survival of about $10 \%$ (1). Over $90 \%$ of PDA instances harbor an oncogenic mutation in the KRAS gene, most commonly $\operatorname{KRAS}^{G 12 D}(2,3)$. Autopsy studies have revealed that over $75 \%$ of the population harbors preneoplastic lesions in the pancreas linked to mutations in $K R A S$, yet pancreatic cancer is relatively rare $(4,5)$. This finding is reproduced in mouse models of the disease, where widespread epithelial expression of oncogenic Kras leads to cancer with long latency. Why some KRAS-mutant lesions maintain an indolent pre-neoplastic state while others progress to deadly invasive cancer is a fundamental gap in knowledge.

A longstanding question has been the identity of the cell of origin to pancreatic cancer. The most frequently utilized genetically engineered mouse models of pancreatic cancer express Kras ${ }^{\mathrm{G} 12 \mathrm{D}}$ broadly across the pancreas epithelium upon Cre recombination. Two of the most common Cre drivers include the

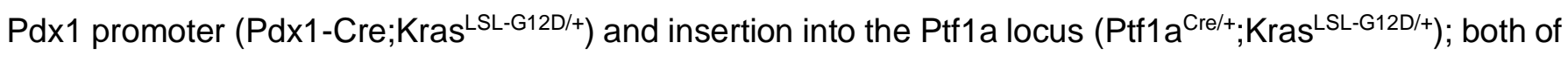
these models are commonly referred to as KC (6) (7). Different precursor lesions to pancreatic cancer have been described in human patients $(8\})$, of which Pancreatic Intraepithelial Neoplasia (PanIN) is the most common. KC mice undergo a stepwise carcinogenesis process that mimics the progression of human disease, including PanIN formation (6) (7). While in mouse models both acinar cells and ductal cells can give rise to pancreatic cancer, acinar cell origin is the most frequent for both PanIN and cancer (9), (10), (11), (12).

Acinar cells are highly plastic - upon tissue damage, they downregulate expression of digestive enzymes and acquire a duct-like differentiation status through a process known as acinar-to-ductal metaplasia (ADM). Acinar cells that have undergone ADM can be distinguished from ductal cells due to their unique expression of acinar progenitor factors (13). In the context of acute injury, ADM is reversible, and the acinar parenchyma is re-established over time. However, expression of oncogenic Kras prevents the recovery of ADM and the duct-like cells instead undergo neoplastic transformation (14). The cell intrinsic mechanisms regulating the balance between cellular plasticity and carcinogenesis have been extensively studied. ADM is driven by fundamental changes in the transcriptional regulation of acinar cells, 
with acinar transcription factors restraining and ductal transcription factors promoting this process (for review see (15)). For example, reduction of expression of the acinar transcription factors Ptf1a, Mist1 or Nr5a2 promote transformation, while forced expression of Mist 1 and Ptf1a protect acinar cells from dedifferentiation (16-21). ADM is also regulated by intracellular signaling, including a requirement for epithelial MAPK activation $(22,23)$. Recently, epigenetic reprogramming driven by oncogenic Kras has emerged as a key determinant of progression/redifferentiation of acinar cells upon injury (24).

While the cell autonomous (i.e., intrinsic) effects of oncogenic Kras activation have been extensively studied, the non-cell autonomous effects are less understood. Here, we set out to investigate how oncogenic Kras-expressing cells affect the microenvironment, which we refer to as "extrinsic" Kras signaling. The transdifferentiation of acinar cells and formation of ADM/PanIN are accompanied by changes in the surrounding microenvironment, with activation of fibroblasts (for review see Helms, 2020, 32014869) and infiltration of immune cells. The latter are largely immune suppressive (25), and include myeloid cells that both suppress $\mathrm{T}$ cell responses and directly promote pancreatic cancer progression $(26,27)$. Myeloid cells support ADM (28) and are required for sustaining ADM and promoting progression to PanIN (29). Conversely, myeloid cells are also required for tissue repair both in the setting of injury and redifferentiation $(29,30)$. Further, experimental induction of acute pancreatitis with its associated inflammation synergizes with oncogenic Kras to accelerate the formation of ADM and PanIN $(31,32)$. Thus, inflammation both accompanies and promotes carcinogenesis, but the relationship between epithelial cells and surrounding stroma in this process remains unclear.

In this study, we investigate how extrinsic signaling mediated by oncogenic Kras regulates the formation and maintenance of the fibroinflammatory stroma and the cellular crosstalk during the initiation of pancreatic cancer. To this end, we have used a genetically engineered mouse model of inducible and reversible oncogenic Kras expression previously described by our group and others $(33,34)$. By exploiting our ability to activate and inactivate oncogenic Kras expression at will, we have dissected the events immediately following the inception of oncogenic Kras expression and observed how continuous oncogenic Kras signaling both maintains acinar transdifferentiation and directs the surrounding microenvironment. We have discovered that fibroblast reprogramming occurs during the earliest stages of carcinogenesis and 
in turn drives the tumor-promoting functional status of myeloid cells infiltrating the pancreas. Consequently, approaches to reprogram fibroblasts during carcinogenesis should be explored to prevent, and possibly reverse, KRAS-driven carcinogenesis.

\section{RESULTS}

\section{Extrinsic signaling by oncogenic Kras reprograms the pancreas microenvironment}

To study the recruitment of immune cells by oncogenic Kras expressing-tumor cells, we used

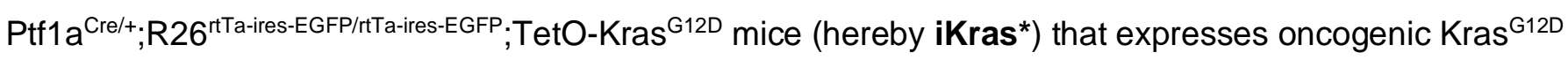
(hereby Kras*) in pancreatic epithelial cells in an inducible and reversible manner upon Doxycycline (DOX) administration (33). Initially, we activated Kras* in adult mice (6-12 weeks old) by feeding iKras* mice or littermate controls (lacking either Cre or Kras* expression) DOX chow for 3 days, 1 week or 2 weeks (See scheme in Fig. 1A). Pancreata from iKras* mice appeared largely histopathologically normal 3 days following Kras* activation, with the parenchyma largely composed of acinar cells and CK19 expression confined to the ducts (Fig. 1B and C and quantification of ADM in Fig. S1A). One week after Kras* induction, we observed focal ADM accompanied by an increase in the proliferation marker Ki67 that became more widespread by 2 weeks (Fig. 1B and Fig. S1B). At the 3-day timepoint, we observed patchy epithelial expression of phosphorylated ERK ( $p-E R K)$, indicating activation of the MAPK pathway (Fig. 1D) in otherwise histologically normal areas. At later time points, areas of apparent ADM had elevated p-ERK staining (Fig. 1D). The limited expression of $p-E R K$ even as all pancreas epithelium express Kras* is consistent with the known requirement of stimulation by various upstream factors to fully activate Kras* signaling, including myeloid-derived EGFR ligands (35)) $(36,37)$.

Next, we investigated the dynamics of immune infiltration and the presence of activated fibroblasts (as marked by expression of smooth muscle actin, SMA). Co-immunofluorescence and immunohistochemistry analysis revealed the presence of macrophages surrounding untransformed $p$-ERK-expressing acinar cells as early as 3 days post-Kras* activation (Fig. 1D and S1C), while T cells were rare at this stage (Fig. 1C and S1D). Macrophages increased by 1 and 2 weeks post-Kras* activation, and T cells were easily detected at these timepoints as well (Fig. 1C, S1C and 1D). Areas of ADM at this stage were also 
surrounded by SMA+ fibroblasts (Fig. 1C and 1D). We then examined the areas of the pancreas that were morphologically normal at the 1-week timepoint (Fig. 1E). Interestingly, high-magnification images revealed morphologically normal clusters of acini with elevated p-ERK surrounded by both macrophages and a thin layer of $\mathrm{SMA}^{+}$fibroblasts, indicating that changes in the microenvironment precede acinar transdifferentiation. Careful analysis of the tissue from the 3-day timepoint also revealed some p-ERKexpressing acini with surrounding macrophages but without $\mathrm{SMA}^{+}$fibroblasts (Fig. 1D). When we evaluated neutrophil infiltration $\left(\right.$ Ly6 $\left.b^{+}\right)$at this timepoint, we observed them more frequently in ADM than in histologically normal areas, suggesting that their recruitment is later in the transdifferentiation process than macrophages (Fig. S1E). Taken together, our findings are consistent with a model whereby macrophage infiltration and $\mathrm{p}$-ERK activation occur in tandem, followed by fibroblast activation and ultimately acinar transdifferentiation.

While the pancreas is home to resident macrophages that expand during carcinogenesis (38), CCR2 ${ }^{+}$ monocytes are also recruited to the pancreas and give rise to macrophages $(39,40)$. To understand the contribution of monocyte-derived macrophages to the establishment of ADM, we treated iKras* mice with the CCR2 inhibitor, PF-04178903, (hereby CCR2i) (41) or vehicle control, concurrently with Kras* activation (Fig. 1F). Tissue was harvested 1 week following treatment. ADM was rare in both cohorts, and we observed no difference in its prevalence (Fig. S1F). There was an $\sim 1 / 3$ decrease in the number of macrophages in the tissue of CCR2i-treated pancreata compared to vehicle controls, consistent with a model by which recruitment of monocyte-derived macrophages had been prevented, while tissue resident macrophages, known to be prevalent at this stage (38), remained unaffected (Fig. 1G and 1H). We observed no difference in the levels of $p$-ERK staining, indicating that infiltrating macrophages are not required to initiate MAPK signaling at this stage (Fig. 1G and 1I), possibly as resident macrophages serve as a sufficient source of EGFR ligands (35). Interestingly, we observed a reduction in the number of activated fibroblasts surrounding p-ERK expressing acinar clusters (Fig. 1G and 1J). These data suggest that monocyte-derived macrophages are recruited through the CCL2/CCR2 axis following epithelial activation of oncogenic Kras and are required for fibroblast activation during Kras*-induced acinar transdifferentiation. 


\section{Epithelial oncogenic Kras* is required to maintain acinar transdifferentiation and fibroblast accumulation.}

Acute pancreatitis synergizes with oncogenic Kras to drive neoplastic transformation (31-33). Accordingly, we placed iKras* and control mice on DOX and then induced acute pancreatitis (see scheme in Fig. 2A). Pancreata in iKras* mice presented with widespread ADM and low grade PanINs (with intracellular mucin accumulation as shown by PAS staining) and accumulation of fibrotic stroma (Fig. 2B and 2C). In contrast, control mice treated in parallel had normal pancreas architecture. iKras ${ }^{\star}$ pancreata were also marked by extensive collagen deposition, fibroblast expansion and activation (as detected by podoplanin and SMA, respectively) and epithelial p-ERK accumulation (Fig. 2C, 2D and 2E). To study the effect of Kras* inactivation on the surrounding microenvironment, we replaced DOX chow with DOX-free chow to inactivate Kras* expression in iKras* mice (for 3 days or 1 week) 3 weeks post-administration of acute caerulein (see scheme in Fig. 2A). The 3-day and 1-week timepoints were chosen to coincide with the early and mid-phases of the pancreatic remodeling process, as we have previously shown (33). As previously described, Kras* inactivation led to a drastic reduction in p-ERK and redifferentiation of acinar cells progressively over time (Fig. 2B, 2E) (29). We then investigated changes in the stroma following inactivation of Kras ${ }^{*}$. We observed a reduction in both total fibroblasts (podoplanin ${ }^{+}$cells) and of activated, $\mathrm{SMA}^{+}$fibroblasts, as well as a reduction in collagen deposition (Fig. 2C, 2D and 2E and quantification in 2F and 2G). These results are consistent with a requirement for continued oncogenic Kras* activity to maintain fibroblast expansion and pancreatic fibrosis.

\section{Extrinsic signaling from Kras* transformed cells drives myeloid polarization}

Myeloid cells infiltrate early during pancreatic carcinogenesis and are required for sustained ADM and progression to PanIN $(28,29,42)$. Therefore, we endeavored to study the effect of Kras* inactivation on myeloid cell infiltration in the pancreas. For this purpose, we placed iKras* and control mice on DOX and then induced acute pancreatitis (See scheme in Fig. 3A). Three weeks later, animals were randomized to DOX or DOX-free chow to inactivate Kras* expression for 3 days or 1 week. We then performed a 
combination of flow cytometry with an antibody panel enriched for myeloid cell markers (Table S1; gating strategy in Fig. S2A) and immunostaining, including multiplex immunofluorescent staining (Opal multiplex IHC, Akoya). As expected, we observed an increase in CD45 ${ }^{+}$immune cells in the iKras* mice at 3w ON compared to control mice (Fig. 3B and S2C). This increase included total myeloid cells $\left(\mathrm{CD}_{4} 5^{+} \mathrm{CD} 11 \mathrm{~b}^{+}\right)$ as well as macrophages $\left(\mathrm{CD} 45^{+} \mathrm{CD} 11 \mathrm{~b}^{+} \mathrm{F} 4 / 80^{+}\right)$and immature myeloid cells $\left(\mathrm{CD} 45^{+} \mathrm{CD} 11 \mathrm{~b}^{+} \mathrm{F} 4 / 80^{-}\right.$ Ly6C + Ly6G+, often referred to as MDSCs) (Fig. 3B, S2B and S2C), consistent with the increase in leukocyte infiltration observed in KC mice (25). Surprisingly, Kras* inactivation resulted in little to no reduction in total immune infiltration, total myeloid cells, or macrophages (Fig. 3B, S2B and S2C). As myeloid cell numbers did not change upon Kras* inactivation, we sought to determine whether their polarization status was affected. For this purpose, we used mass cytometry (CyTOF) which allowed us to use a panel of 20 antibodies concurrently (see Table S2). We limited the scope of the CyTOF experiment to the 3 weeks $\mathrm{Kras}^{*} \mathrm{ON}(\mathrm{N}=2)$ and 3 days $\mathrm{OFF}(\mathrm{N}=3)$ timepoints in order to highlight the short-term effect of Kras* inactivation, prior to extensive tissue remodeling. We visualized the multi-dimensional CyTOF data using tSNE plots (t-distributed stochastics neighbor embedding) and identified 16 distinct immune cell clusters (Fig. 3C and S2D). We observed no significant change in the T cell clusters upon Kras* inactivation, although there was a trend towards an increase in CD4 ${ }^{+} \mathrm{T}$ cells (Fig. S2E). The myeloid immune landscape was complex, with multiple populations, including heterogeneous macrophage subtypes (Fig. 3C, 3D and S2D). While some populations did not change or tended towards an increase when we compared Kras* ON to Kras* OFF samples, (such as iNOS ${ }^{+}$macrophages, Fig. S2F), other populations drastically decreased. Notably, CCR $1^{+} \mathrm{CD} 206^{+}$macrophages, immunosuppressive ARG1+ monocytic macrophages and MDSCs, defined as CD45+CD11b+F4/80-Ly6C+Ly6G+, decreased upon Kras* inactivation (Fig. 3D). The decrease in macrophages and ARG1+ macrophages was also validated by coimmunofluorescent and multiplex immunofluorescent staining (Fig. 3E, S3A, S3B and S3C). Furthermore, JAK/STAT3 signaling, known to promote the immune-suppressive function of macrophages, (43), is similarly regulated by epithelial oncogenic Kras (Fig. 3F).

As CyTOF and immunostaining are limited by available antibodies, we performed single cell RNA sequencing (scRNAseq) to fully elucidate how epithelial Kras* expression alters the microenvironment, 
with special interest in infiltrating myeloid cells. We harvested pancreata from mice with Kras* ON for 3 weeks plus 3 days $(\mathrm{N}=2$, pooled for submission) or $\mathrm{ON}$ for 3 weeks and then OFF for 3 days $(\mathrm{N}=3$, pooled for submission). The experiment was designed so that pancreata were harvested and processed at the same time to avoid batch effects. The multidimensional scRNAseq data included a total of 5,073 cells overall, with 1,984 cells from the 3 w ON sample and 3,089 cells from the $3 d$ OFF sample. The data was analyzed using the Seurat package in R (version 3.2.2) and visualized by UMAP (uniform and manifold approximation and projection) (Fig. 3G). By comparing the transcriptome of each cluster to known markers of epithelial, immune, and stromal cell types (Fig. S4A), we were able to identify acinar cells, CK19+ epithelial cells, fibroblasts, endothelial cells, and multiple populations of CD45 immune cells. Similar varieties of cells were present in both the ON and OFF condition, allowing us to compare gene expression changes upon inactivation of Kras* within each cell population. We first assessed gene expression changes in the macrophage population and observed changes in polarization markers (Fig. $\mathbf{3 H}$ ). Notably, tumor-associated macrophage (TAM) markers such as Arg1 and Ccr1 were downregulated upon Kras* inactivation. We also observed downregulation of Apolipoprotein $E(A p o e)$ - a secreted protein that our group recently described as highly expressed in TAMs and as promoting immune suppression in invasive pancreatic cancer (44). Additionally, we observed downregulation of the complement genes C1qa, C1qb, C1qc and the transcription factor Trem2, which together define TAMs in several malignancies (45). Our group has also recently described a population of $\mathrm{Clqa}^{+} \mathrm{C1qb^{+ }} \mathrm{Trem}^{+}$macrophages enriched in human and mouse pancreatic cancer both at the primary tumor and in liver metastases (46). These findings are consistent with TAM gene expression markers being activated in macrophages during the onset of neoplasia. Interestingly, inactivation of $\mathrm{Kras}^{*}$ induces a "repair-associated" gene expression program, including Tgfb, /110, I/4, Pdgfb and Mmps (Fig. 3H). Together, we show that oncogenic Kras inactivation does not alter overall immune infiltration, but drastically reprograms macrophage gene expression.

\section{Epithelial Kras* drives inflammatory reprogramming of pancreatic fibroblasts.}

We next sought to understand whether modulation of $\mathrm{Kras}^{*}$ expression in epithelial cells influenced extracellular crosstalk in such a way as to account for our observed changes in macrophage 
reprogramming. To achieve this, we averaged the expression levels of genes from each cell population and looked for expression of known ligand and receptor pairs using a published list further curated in our laboratory $(47,48)$. Pairing of ligand and receptor-expressing populations gave us a list of potential predicted interactions within the tissue (Fig. 4A). We then plotted interactions that were significantly downregulated upon Kras* inactivation. Strikingly, the vast majority of Kras ${ }^{*}$-driven interactions connected fibroblast ligands with receptors on epithelial cells and a multitude of immune cells (Fig. 4B, 4C). These data suggest that fibroblasts are reprogrammed when exposed to Kras*-expressing epithelial cells, becoming a key signaling hub driving changes in the immune microenvironment. We identified multiple cytokines and chemokines expressed in fibroblasts in an epithelial Kras*-dependent manner (Fig. 4D); among those, we selected the genes that were mainly expressed by fibroblasts, including $/ / 33, \| 6, \mathrm{Cxc} / 1$ and the inflammatory mediators Saa1 and Saa3 (the ortholog of human SAA1). While expression of these factors was not confined to fibroblasts, it was highest in this cell population (Fig. 4E and S4B). Conversely, the respective receptors for these secreted factors were expressed by immune cells, including $C x c r 2$ (CXCL1 receptor) on immature myeloid cells, II6r (IL6 receptor), P2rx7 and Scarb1 (SAA3 and SAA1 receptors) on several myeloid populations, and //1rl1 (IL33 receptor also known as ST2) on macrophages, Tregs, mast cells, and innate lymphoid cells type 2 (ILC2). Thus, fibroblasts extrinsically reprogrammed by $\mathrm{Kras}^{*}$ epithelial cells express inflammatory molecules that bind receptors on myeloid cells, in turn activating their canonical downstream signaling pathways including JAK/STAT3 signaling. Accordingly, p-STAT3, a readout of active JAK/STAT3 signaling, is elevated in macrophages infiltrating PanIN-bearing pancreas (Fig. 3F).

To validate the mechanism of fibroblast reprogramming, we used an in vitro approach. We harvested conditioned media from iKras* cells derived from a Ptf1a ${ }^{\text {Cre/+; }}$ R26 ${ }^{\text {rTa-ires-EGFP/rtTa-ires-EGFP;TetO- }}$ Kras $^{\mathrm{G} 12 \mathrm{D}} ; \mathrm{P} 53^{\mathrm{R} 172 \mathrm{H} /+}\left(\right.$ (Kras $\left.^{\star} P 53^{\star}\right)$ mouse tumor (49). In brief, iKras ${ }^{\star} \mathrm{P53}{ }^{\star}$ cells (49) were grown in presence of DOX. Then, media was changed to either DOX-containing or DOX-free media, thus maintaining Kras* expression or inactivating it, respectively. After 48-72 hours, we harvested CM from each condition and 
boiled half of it to denature heat-labile components. CM was then administered to cultured primary mouse fibroblasts (CD1WT and B6318) derived from healthy adult pancreata as previously described (50) (44)) (Fig. 5A). Compared to regular media (control), CM from iKras* cells in presence of DOX induced expression of $\mathrm{CxCl1}$, II6, I/33 and Saa3 in fibroblasts (Fig. 5B and S5A), while CM from iKras* cells grown without DOX failed to induce a similar level of expression. To distinguish between a Kras* ${ }^{*}$ dependent protein factor or metabolite signaling to fibroblasts, we compared intact CM with boiled CM, and found that the latter induced $/ / 6$ but none of the genes encoding the cytokines of interest (Fig. 5B and S5A). Thus, heat-labile factors such as proteins are likely involved in activating inflammatory gene expression, though a cancer cell-derived, Kras*-dependent metabolite may be responsible for II6 induction. Oncogenic Kras regulates the intracellular metabolome of pancreatic cancer cells (34). We enquired whether the extracellular metabolome is similarly dependent on expression of oncogenic Kras. Indeed, mass spectrometry-based metabolomics profiling revealed numerous extracellular metabolites whose abundance changed depending on Kras* expression (Fig. S5B and S5C). Among these, several released metabolites have been reported to act as direct extracellular signaling molecules (e.g. pyruvate, lactate, alpha-ketoglutarate) (Fig. S5D), while, alternatively, the decreased abundance of other metabolites may impact signaling downstream of mTOR (e.g. arginine, isoleucine, cystine, glutamine) (Fig. S5C) (51-54). We then interrogated the extracellular metabolite composition following incubation of the iKras* conditioned medium from the various conditions described above. We observed that the lactate concentration was not affected while pyruvate was depleted upon culturing with fibroblasts. Thus, it appears that fibroblasts consume pyruvate from the medium, an intriguing finding given that fibroblasts serve as a source of pyruvate in breast cancer (55).

We then interrogated the list of secreted factors expressed by transformed cells (likely within the CK19+ epithelial compartment) in the single cell sequencing data. We noted, among others, expression of $H$ begf, Tnf, Pdgf, Hgf and II6, while the corresponding receptors were expressed in fibroblasts (Fig. 5C). Expression of Hbegf, Tnf and Pdgfa was higher in epithelial cells, whereas Hgf, $I 16$ and Pdgfb were higher in fibroblasts. Given the multitude of factors and their pleiotropic effect on intracellular pathway activation, 
we elected to block the common downstream effector pathways MAPK and JAK/STAT3 in fibroblasts rather than targeting individual secreted factors. We then repeated the experiment described above, this time inhibiting MAPK signaling (using Trametinib; MEKi) or JAK/STAT signaling (using Ruxolitinib; JAKi) (Fig. 5D and S5E). CM-induced fibroblast expression of $C x c / 1, / / 33$ and $/ / 6$ was inhibited by both MEKi and JAKi, while Saa3 expression was only inhibited by JAKi (Fig. 5E and S5F). Thus, tumor cell factors expressed upon Kras* activation reprogram fibroblasts by activating MAPK and JAK/STAT signaling to induce expression of a panel of inflammatory cytokines.

\section{DISCUSSION}

Pancreatic cancer is associated with an extensive fibroinflammatory reaction that often constitutes over $80 \%$ of the tumor volume (for review see (8)). The interplay between tumor cells and components of the microenvironment promotes tumor growth and malignancy, and as such, is an area of intense investigation. What remains to be understood is how the stroma forms within the pancreas, as well as the events that lead from normal tissue to precursor lesions, and ultimately, malignant disease. Mutations in the KRAS gene are present in the majority of human pancreatic cancer instances (56). Further, those mutations occur early during carcinogenesis, and are prevalent in PanIN in the human pancreas (57). Interestingly, KRAS mutations occur spontaneously in a large proportion of individuals, increasing with age, yet pancreatic cancer remains a relatively rare disease $(4,5)$.

In the current study, we set out to understand how the interplay between epithelial cells expressing oncogenic Kras and the surrounding components of the pancreatic microenvironment regulate the balance between tissue repair and carcinogenesis. Using the iKras* genetically engineered mouse model (33) where oncogenic Kras can be activated and inactivated at will, we were able to follow changes in the pancreas at regular intervals immediately following the activation of oncogenic Kras. We found that Krasdependent signals drive infiltration of monocyte-derived macrophages in the pancreas and activation of pancreatic fibroblasts. While changes in macrophages and fibroblasts appeared to occur simultaneously, we show that there is an epistatic relationship whereby inhibition of monocyte recruitment to the pancreas 
(by inhibition of CCR2) leads to reduced fibroblast activation, despite intact epithelial MAPK signaling. This finding also shows that recruitment of monocytes to the pancreas is important during the early stages of carcinogenesis, even as resident macrophages are equally required for lesion formation (38).

Given that myeloid cells are abundant during the early stages of carcinogenesis while $\mathrm{T}$ cell infiltration is rare, we focused the scope of this study on understanding epithelial cell/myeloid cell crosstalk. For this purpose, we let mice develop early pancreatic lesions and then inactivated oncogenic Kras. Our group has previously shown that inactivation of oncogenic Kras during these early stages of carcinogenesis leads to tissue repair over the course of two weeks, a process that requires macrophages $(29,33)$. We first hypothesized that continuous oncogenic Kras expression was necessary to maintain myeloid/macrophage infiltration in the pancreas. Contrary to our expectations, inactivation of oncogenic Kras had no effect on the number of myeloid cells present in the pancreas. However, analysis of the phenotype of infiltrating myeloid cells revealed a profound change in polarization. In the presence of oncogenic Kras, infiltrating macrophages express a series of markers that are consistent with tumor associated macrophages (TAMs), indicating that polarization of tumor-promoting macrophages occurs relatively early, prior to the formation of malignant disease. For example, macrophages in the neoplastic pancreas express the enzyme Arginase 1 (Arg1) and CD206/MRC1, while expression of iNOS, a marker of proinflammatory macrophages, is low. However, inactivation of oncogenic Kras leads to a reduction in Arg1+ macrophages.

To more comprehensively depict the relationship between epithelial and myeloid cells in early pancreatic tumorigenesis, we performed single cell RNA sequencing (scRNAseq) of iKras* mice either with active expression of oncogenic Kras or following 3 days of inactivation of oncogenic Kras. These timepoints were ideal as we have previously shown that at this interval, inactivation of oncogenic Kras causes levels of Kras-GTP (active Kras) to return to baseline while tissue repair is minimal, preventing us from comparing drastically different tissues (33). We then probed our scRNAseq dataset for known ligand-receptor pairs to determine which cell-cell signals were mediated by oncogenic Kras and responsible for macrophage repolarization. Interestingly, most of the signals that changed upon inactivation of oncogenic Kras were derived from fibroblasts, rather than epithelial cells. Fibroblasts were a source of multiple cytokines: some were also expressed by other cell types (I/33 and I/6), while others were uniquely fibroblast-specific (Cxc/1, 
Saa1 and Saa3). Recently, IL33 has been described as expressed by epithelial cells during the early stages of carcinogenesis and noted to promote neoplastic progression (24); interestingly, we found that IL33 is also highly expressed by fibroblasts in early tumorigenesis stages, while its receptor is on multiple immune cell populations. Fibroblasts are also a source of IL6, with a known role in pancreatic cancer progression (58-60); Saa3 (ortholog to human SAA1), an apolipoprotein required for neoplastic progression (61) and CXCL1, which has been studied in epithelial cells, and shown to be a key moderator of $\mathrm{T}$ cell exclusion in malignant disease (62). In our study, fibroblasts emerged as mediators of epithelial/immune cell crosstalk during the onset of pancreatic carcinogenesis. To mechanistically dissect the fibroblast reprogramming process, we cultured primary mouse pancreatic fibroblasts with conditioned media from iKras* ${ }^{*} 53^{*}$ tumor cells (49) expressing Kras* ON or OFF. We found that even in culture, fibroblasts are reprogrammed when exposed to CM from oncogenic Kras-expressing epithelial cells. Interestingly, while the majority of cytokines we assessed in fibroblasts required a heat labile component of the conditioned media, $/ 16$ did not, implying that a combination of Kras*-dependent signals are required for establishing a complete reprogramming of pancreatic fibroblasts, potentially including both peptide and metabolic secreted factors. Elucidating further details on these tumor-derived signals merits further exploration.

The role and origin of fibroblasts in pancreatic cancer remains poorly understood. Fibroblasts have been found to secrete a number of cytokines that influence the immune milieu (for example, CXCL12, which has been shown to reduce $\mathrm{T}$ cell infiltration in pancreatic cancer), and as such they promote cancer growth (63). However, in other models, fibroblast depletion promotes carcinogenesis (64). These contradictory findings might be explained by the heterogeneity of fibroblast populations. In recent years, the nature and origin of fibroblasts in advanced disease have been addressed by several studies, and previous assumptions regarding these cell populations have been challenged as a consequence. Cancerassociated fibroblasts (CAFs) have been long assumed to derive from a pancreatic stellate cell (PSC) population in the pancreas (similar to hepatic stellate cells), but recent lineage tracing work by our group has revealed that a substantial proportion of CAFs derive from perivascular fibroblasts present in the normal pancreas (65). Accordingly, a lineage tracing study following PSCs in pancreatic cancer showed 
that they only contribute to a small subset of CAFs (66). In vitro characterization and, more recently, scRNAseq studies have identified CAF subsets with specific transcriptional signatures and functional roles (67-69). Less studied is the role of fibroblasts in the neoplastic pancreas; our current results show that neoplasia-associated fibroblasts, reprogrammed by epithelial cells expressing oncogenic Kras, shape the immune microenvironment during the onset of carcinogenesis, likely initializing the immune suppressive nature of pancreatic neoplasia (25) (See Scheme in Fig. 6).

Recently, oncogenic Kras expression in pancreatic cancer has been associated with immune evasion (70). However, it remains to be seen whether the pancreatic cancer-associated immune response maintains its dependance on fibroblasts during late stages of carcinogenesis. In lung cancer, KRAS and MYC cooperate to shape the immune microenvironment (71); whether fibroblasts are required as signaling mediators in Kras-driven lung cancer and other diseases is not known.

In this study, we close the loop on communication between epithelial cells, fibroblasts and immune cells. Reprogramming of myeloid cells to alleviate the profound immune suppression of pancreatic cancer is a key concept in potential therapeutic approaches $(72,73)$. Unfortunately, the initial results from clinical trial testing of a CD40 agonist administered to reprogram myeloid cells combined with immune checkpoint inhibition and chemotherapy were disappointing (74), pointing to the need for yet additional avenues by which to target the microenvironment. Our current work suggests that fibroblast reprogramming should be considered in high-risk patients to prevent malignant progression and could also be explored to prevent tumor relapse in surgical patients. Finally, our study provides another piece of the puzzle in our understanding of the events that lead to the onset and progression of pancreatic cancer, and as such contribute to our fundamental knowledge of this deadly disease. 


\section{ACKNOWLEDGEMENT}

We thank Michael Scales and Dr. Benjamin L. Allen for providing the B6318 mouse wild-type fibroblast cell line. We thank Dr. Beth Moore for providing us with the CCR2 inhibitor. We thank Daniel Long for his histological services. This project was supported by NIH/NCI grants R01CA151588, R01CA198074, the University of Michigan Cancer Center Support Grant (NCI P30CA046592), the American Cancer Society to MPM and U01CA-224145 to MPM and HCC. YZ was funded by NCI-R50CA232985. AVD was supported by Rackham Merit Fellowship, Cellular Biotechnology Training Program (T32GM008353) and the NCI F31-CA247037. KLD, NGS and VRS were funded by the Cancer Biology Training Program T32CA009676. NGS is also a recipient of the American Cancer Society Postdoctoral Award PF-19-096-01 and the Michigan Institute for Clinical and Healthy Research (MICHR) Postdoctoral Translational Scholar Program fellowship award. REM was supported by the NIH Cellular and Molecular Biology Training Grant T32-GM007315 and the Center for Organogenesis Training Program (NIH T32 HD007505). S.T \& A.R were supported by institutional startup funds from the University of Michigan, $\mathrm{NCl}$ grants R37CA214955 \& NCI P30CA046592 and a Research Scholar Grant from the American Cancer Society (RSG-16-005-01). SBK was supported by NIH T32-GM113900 and NCI F31-CA247076. SAK was supported by F31CA24745701. CAL was supported by the NCI (R37CA237421, R01CA248160) and UMCCC Core Grant (P30CA046592). FB was funded by the Association of Academic Surgery Joel Roslyn Award. TF was supported by (K08CA201581). Metabolomics studies performed at the University of Michigan were supported by NIH grant DK097153, the Charles Woodson Research Fund, and the UM Pediatric Brain Tumor Initiative. This project was also supported by the Tissue and Molecular Pathology and Flow Cytometry Shared Resources at the Rogel Cancer Center and the University of Michigan DNA Sequencing Core. CyTOF was performed at the University of Rochester University of Rochester Medical Center Flow Cytometry Shared Resource and at the Indiana University Simon Cancer Center Flow Cytometry Service.

\section{AUTHOR CONTRIBUTIONS}

MPM directed the study. AVD, YZ and MPM designed experiments. AVD, KLD, KLB, WD, VIN, REM, 
ELLO, JL, WY, SBK, MB, FL, CAL, HCH, TLF performed the experiments and generated data. AVD, KLD, WD, NGS, ST, JL, VRS, SAK, ACN, FL, AR, FB, YZ and MPM analyzed and interpreted data. AVD, YZ and MPM wrote the manuscript, then all authors edited and approved the final version.

\section{CONFLICT OF INTEREST STATEMENT}

CAL has received consulting fees from Astellas Pharmaceuticals and is an inventor on patents pertaining to KRAS regulated metabolic pathways, redox control pathways in pancreatic cancer, and targeting the GOT1-pathway as a therapeutic approach.

\section{METHODS}

\section{Mice}

Mice were housed in the specific pathogen-free animal facility at the Rogel Cancer Center, University of Michigan, and overseen by the unit for laboratory animal medicine (ULAM). Ptf1a(p48)Cre;Rosa26 ${ }^{\text {rTa/rTa }}$ mice were crossed to TRE-Kras ${ }^{\mathrm{G} 12 \mathrm{D}} ; \mathrm{R} 26^{\mathrm{rTa} / \mathrm{rTT}}$ to generate the p48-Cre;TRE$\mathrm{Kras}^{\mathrm{G} 12 \mathrm{D}} ; \mathrm{R} 26^{\mathrm{rtTa} / \mathrm{rTa}}\left(\mathrm{iKras}^{*}\right)$, as described (33). Expression of Kras* was induced in adult mice (8-14 weeks old) by replacing regular chow with Doxycycline chow (Bio-Serv, 1gm/kg). Acute pancreatitis was induced by administering eight hourly doses of caerulein $(75 \mu \mathrm{g} / \mathrm{kg}$, Sigma-Aldrich) intraperitoneally for two consecutive days. For CCR2 inhibition, PF-04178903 (Pfizer, Inc, provided by Dr. Beth Moore) (Gurczynski, 2019, 30498200) was administered subcutaneously twice a day for 7 days at 50ug per dose in $100 \mu$ l of PBS. PBS was used as control. All animal studies were conducted in compliance with the guidelines of the Institutional Animal Care \& Use Committee (IACUC) at the University of Michigan.

\section{Histology and Immunohistochemistry}

Pancreatic tissue samples from experimental and control mice were fixed in $10 \%$ neutral-buffered formalin (FisherBrand) overnight and then embedded in paraffin and sectioned into slides. Hematoxylin and Eosin (H\&E), Gomori's Trichome, Periodic Acid-Schiff (PAS) and Immunofluorescence (IF) staining were performed as previously described (33). For immunohistochemistry, fresh cut paraffin sections were 
re-hydrated using 2 series of xylene, 2 series of $100 \%$ ethanol and then 2 series of $95 \%$ ethanol. Water was used to wash all residues from previous washes. Antigen retrieval was performed using Antigen Retrieval CITRA Plus (BioGenex) and microwaved for total 8 minutes. Upon cool down, sections were blocked using 1\% BSA in PBS for 30 minutes and then primary antibodies (for details see Supplementary Table 1) were used at their corresponding dilutions. Primary antibody incubation was performed at $4^{\circ} \mathrm{C}$ overnight. Biotinylated secondary antibodies were used in 1:300 dilution and applied to sections for 45 minutes at room temperature. Following secondary antibody incubation, sections were incubated for 30 minutes with the $A B C$ reagent from Vectastain Elite $A B C$ Kit (Peroxidase), followed by DAB (Vector). For immunofluorescence (IF), Alexa fluor secondary antibodies (Invitrogen) were used, then slides were mounted with Prolong Diamond Antifade Mountant with DAPI (Invitrogen). TSA Plus Fluorescein system (PerkinElmer) was used in IF for mouse primary antibodies. Olympus BX53F microscope, Olympus DP80 digital camera, and CellSens Standard software were used for imaging. Quantification of positive cell number or area was done by ImageJ using 3-5 images/slide (200x or $400 x$ magnification) taken from 2-4 samples per group.

\section{Multiplex IHC Staining and Analysis}

Multiplex immunohistochemistry staining was performed on paraffin embedded pancreatic tissue sections as follows. Slides were baked in a hybridization oven for one hour at 60 degrees Celsius, cooled for 10 minutes at room temperature, then dipped sequentially $(x 3)$ into xylene for 10 minutes each for removal of paraffin. Slides were then rehydrated in alcohol with dilutions of $100 \%, 95 \%$, then $70 \%$ for 10 minutes each, followed by a wash in deionized water for 2 minutes. Slides were then placed in neutral buffered formalin for 30 minutes. The slides were then washed for 2 minutes in deionized water then microwaved at $100 \%$ power in Rodent Decloaker (Biocare Medical) for 30 seconds, the power level was reduced to $20 \%$ and microwaving continued for an additional 10 minutes followed by a resting step of 15 minutes at room temperature. Microwaving continued at $10 \%$ power for an additional 10 minutes. Prior to microwaving with Rodent Decloaker, plastic wrap was secured on top of the microwave-proof slide box with rubber bands and a partial opening for steam escape to prevent loss of solution. After the last 
microwaving step, slides were left to cool until slides and solution achieved room temperature. The multiplex staining was performed for each primary-color combination. Sides were placed in a deionized water wash for two minutes followed by a TBST wash for 2 minutes. Slides were placed in a slide incubation chamber and Bloxall was applied for 10 minutes followed by an additional blocking step of $1 \%$ BSA (in TBST) for 20 minutes, primary antibody was applied after tapping slide to remove the primary antibody and was left to incubate for 1 hour, slides were washed in TBST (x3) for 2 minutes each, secondary antibody was applied, followed by TBST wash (x3) for 2 minutes each, Opal color was applied for 10 minutes and a TBST wash (x3) for 2 minutes each was performed. The slides were then microwaved with either AR6 or AR9 for 45 seconds at $100 \%$ followed by 15 minutes at $20 \%$. The previous steps were then repeated for each of the following antibodies and Opal colors in exact listed order: F480 at 1:600 (abcam ab6640), CD3 at 1:400 (Dako A0452)-TSA 520, CD8 at 1:400 (Cell Signaling 98941), Arg1 at 1:100 (Cell Signaling 93668), CK19 at 1:400 (Max Plank Institute Troma III). After the last application of multiplex was completed, sides were washed as above and placed in AR6, then microwaved. After cooling the slides were washed in deionized water followed by TBST for 2 minutes each. Opal spectral DAPI solution was applied ( 3 drops diluted in $1 \mathrm{~mL}$ of TBST for 10 minutes followed by a wash in TBST for 30 seconds. Coverslips were mounted with Prolong Diamond, slides were left to lie flat overnight away from light. If the entire multiplex could completed without interruption, the slides were left in AR6 or AR9 after a microwaving step, covered from light until the next day. All primary antibodies were diluted in 1\% BSA and all TSA Opal colors were diluted in TSA diluent at 1:50.

The Mantra Quantitative Pathology Work Station was used to image sections of each of the slides. One to three images per slide was captured at $\times 20$ magnification. Cube filters (DAPI, CY3, CY5, CY7, Texas Red, Qdot) were used in taking each image capture. All images were analyzed using inForm Cell Analysis software (Akoya Biosciences). Sixty-three images of encompassing the 26 different control and experimental slides were batched analyzed after using a mouse formulated library consisting of each single TSA fluorophore listed above. Unmixing was performed and no spectral overlap was found between fluorophores. Using inForm version 2.3.0 training software, cell compartments were segmented into nucleus, cytoplasm, and membrane. DAPI was used to identify the nucleus of the cells and determine their 
shape and size. The cytoplasm was segmented using Arg1 (Opal 650), F480 (Opal 540), and CD3 (Opal 520). The inner distance to the nucleus was set at zero pixels and the outer distance of the nucleus was set at 6 pixels. The membrane was segmented using CK19 (Opal 690) with the max cell size set at 25 pixels from nucleus to the membrane, each pixel is 0.496 microns. $X$ and $Y$ coordinates were assigned to each identified cell in each image. Cell phenotypes (Tcell, macrophage, epithelial cell, acinar cell, other cell) were manually selected at random throughout the 63 images. Tcell, macrophage, and epithelial cells were selected based on single staining of CD3 (Opal 520), F480 (Opal 540), and CK19 (Opal 690) respectfully. Other cells were manually selected based on the lack of staining of the above listed fluorophores and acinar cells were labeled based on the lack of listed fluorophores and tissue morphology. Fluorescent intensity of Arg1 (Opal 650) in the nucleus at a max threshold of 200 and a positivity threshold level of 13 was used to identify Arg1+ cells. R programs were used to make complex phenotypes by combining the primary cell phenotypes (Tcell, macrophage, epithelial cell, acinar cell, and other cell) and the positivity thresholds for CD8+ and Arg1+.

\section{Flow cytometry}

Pancreata were harvested and dissociated to single cells by mincing the tissue finely using scissors followed by Collagenase IV (1 mg/ml, Sigma) digestion for 30 minutes at $37^{\circ} \mathrm{C}$ while shaking. A 40 um mesh strainer was used to separate single cells. RBC lysis buffer (eBioscience) was used to lyse all the red blood cells. Live cells were stained for surface markers using antibodies listed in Supplemental Table 2. The cell were either fixed after the primary antibody staining and use for analysis or the cells were fixed and permeabilized before intracellular staining using antibodies (Table S2). Flow-cytometric analysis was performed on the Cyan ADP analyzer (Beckman coulter) and the ZE5 analyzer (Bio-Rad). Data was analyzed using the FlowJo v10 software.

\section{CyTOF}

Pancreas was harvested and disrupted to single cells as described above. Three mesh strainers were used: 500um, 100um and 40um, to separate single cells. Cells were washed twice in PBS and incubated 
with Cell-ID cisplatin (1.67 umol/L) for $5 \mathrm{~min}$ at room temperature (RT), as a viability marker. Surface and intracellular staining was performed as detailed in manufacturer instructions (Fluidigm) with the antibodies listed in Table 2. Cell were shipped in intercalator buffer on ice overnight to the Flow Cytometry core at the University of Rochester Medical Center, where sample preparation was finalized, and CyTOF2 Mass Cytometer (Helios) analysis was performed. Data analysis was performed using the Premium CytoBank Software (cytobank.org) and R studio using the cytof workflow from Nowicka M. Et. al. (75).

\section{Single-cell RNA sequencing}

Pancreatic tissues were mechanically minced and enzymatically digested with collagenase IV (1 mg/ml in RPMI). Cell suspensions were subsequently filtered through $500-\mu \mathrm{m}, 100-\mu \mathrm{m}$, and $40-\mu \mathrm{m}$ mesh to obtain single cells. Dead cells were removed using the MACS Dead Cell Removal Kit (Miltenyi Biotec). The resulting single cell suspensions were pooled by experimental group (Kras ON/Kras OFF). Singlecell complementary DNA libraries were prepared and sequenced at the University of Michigan Advanced Genomics Core using the 10× Genomics Platform (Raw and processed data are available at

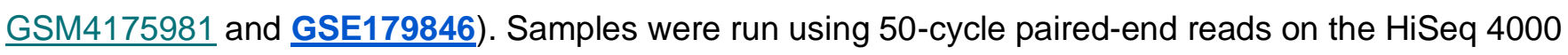
(Illumina) to a depth of 100,000 reads. The raw data were processed and aligned by the University of Michigan DNA Sequencing Core. Cell Ranger count version 3.0.0 was used with default settings, with an initial expected cell count of 10,000. R version 3.6.2, RStudio version 1.2.5033, and R package Seurat version 3.2.2 were used for scRNA-seq data analysis (RStudio Team RStudio: Integrated Development for R (RStudio, 2015); http://www.rstudio.com/; R Core Development Team R: A Language and Environment for Statistical Computing (R Foundation for Statistical Computing, 2017); https://www.Rproject.org/ (76) (77) ). Data were initially filtered to only include cells with at least 100 genes and genes that appeared in more than three cells. Data were normalized using the NormalizeData function with a scale factor of 10,000 and the LogNormalize normalization method. Data were then manually filtered to include only cells with 1,000-60,000 transcripts and $<15 \%$ mitochondrial genes. Variable genes were identified using the FindVariableFeatures function. Data were scaled and centered using linear regression of transcript counts. PCA was run with the RunPCA function using the previously defined 
variable genes. Cell clusters were identified via the FindNeighbors and FindClusters functions, using dimensions corresponding to approximately $90 \%$ variance as defined by PCA. UMAP clustering algorithms were performed with RunUMAP. Clusters were defined by user-defined criteria. The complete $R$ script including figure-specific visualization methods is publicly available on GitHub (https://github.com/PascaDiMagliano-Lab/).

For Interactome analysis, ligand-receptor pairs were defined based on a curated literature-supported list in Ramilowski et al. (47), further curated as described in (48). The average expression values of ligands and receptors in each cell population for both experimental groups (Kras ON/Kras OFF) were calculated individually, and ligands and receptors expressed below a user-defined threshold (median average expression) were removed from analysis. Ligand-receptor pairs were also excluded if the ligands and receptors were not expressed in both experimental groups. Differences in the ligands and receptors between groups were determined using the Wilcoxon ranked test, and $\mathrm{P}$ values were adjusted for multiple comparisons using the Bonferroni correction method. Ligands and receptors were considered significantly different if $P<0.05$. The resulting data table was visualized using Cytoscape (version 3.7.2) software (78). The complete R script is publicly available on GitHub (https://github.com/PascaDiMagliano-Lab/). The Circos plot was built with the Circos software (version 0.69-9) and the heatmap values within the circus plot displays the average expression of each fibroblast ligand and their corresponding receptor across the iKras* pancreatic tissue.

\section{Cell culture}

All cell lines were cultured in DMEM with 10\% Fetal Bovine Serum and 1\% Penicillin Streptomycin. The tumor cell line (9805) was derived from an iKras*P53* (ptf1a-Cre; TetO-Kras ${ }^{\text {G12D }}$;Rosa26 ${ }^{\text {rtTa/+; }}$ p53 ${ }^{\text {R172H/+) }}$ pancreatic cancer (49). The fibroblasts cell lines, CD1WT and B6318, were derived from wild type pancreata of a mixed or C57BL/6J background, respectively. The 9805 cell line was maintained in Doxycycline-containing $(1 \mathrm{ug} / \mathrm{mL})$ medium. To generate conditioned media, fresh medium containing Doxycycline (Kras* ON) or without Doxycycline (Kras* OFF) was replaced and harvested after 2-3 days based on cell confluency. The media were then centrifuged ( $300 \mathrm{G}, 10$ minutes at $4^{\circ} \mathrm{C}$ ) to remove 
contaminating cancer cells. The CM was used to culture fibroblasts with a 1:1 ratio of CM to normal DMEM for 2-3 days. An aliquot of the conditioned media before and after culturing fibroblasts was collected for metabolomics analysis (described below). To test the effect of heat labile factors, media were boiled for 10 mins to denature secondary and tertiary peptide structures. For inhibitor experiments, Ruxolitinib (INCB018424, Selleckchem) at $0.1 \mu \mathrm{M}, 0.5 \mu \mathrm{M}$ and $5 \mu \mathrm{M}$ or Trametinib (GSK1120212, Selleckchem) $0.1 \mu \mathrm{M}, 0.5 \mu \mathrm{M}$ and $2 \mu \mathrm{M}$ or vehicle control were added to the medium.

\section{Quantitative RT-PCR}

RNA was extracted using the QIAGEN kit. RNA samples went through Reverse Transcription-PCR (RTPCR) using the cDNA kit (Applied Biosystems). cDNA samples for quantitative Real Time PCR were prepared using a mix of 1X Fast-SYBR Green PCR Master Mix (Applied Biosystems) and the primers listed in Table 4. The reaction conditions were used as previously described (Collins et al. 2012). Cyclophilin A (Ppia) was used as housekeeping control.

\section{Western Blot}

Cells were lysed using RIPA buffer (Sigma-Aldrich) with protease and phosphatase inhibitors (SigmaAldrich). Protein was quantified and the same amount of protein was loaded to the wells in a $4-15 \%$ SDSPAGE gel (BioRad). Protein was transferred to a PVDF membrane (BioRad), that was blocked with milk and then incubated with primary antibodies listed in Supplementary Table 1 overnight. HRP-conjugated secondary anti- rabbit and anti-mouse (1:5000) were used and detected by using the enhance Chemiluminescent Substrate (PerkinElmer). The bands were visualized using the ChemiDoc Imaging System (BioRad).

\section{Metabolomics analysis}

The conditioned medium from tumor cells and fibroblasts (described above) was aspirated and $1 \mathrm{ml}$ of $80 \%$ methanol -cooled in dry ice- was added per well. The plates were incubated on dry ice for $10 \mathrm{~min}$, then scraped and transferred to sample tubes. The samples were vortexed and centrifuged for $10 \mathrm{~min}$ at 
$13,000 \times g, 4^{\circ} \mathrm{C}$. Then, $1 \mathrm{ml}$ of the supernatant was aspirated from each tube, transferred to a tightly capped sample tube, and stored at $-80^{\circ} \mathrm{C}$ until analysis.

Samples were run on an Agilent 1290 Infinity II LC -6470 Triple Quadrupole (QqQ) tandem mass spectrometer (MS/MS) system with the following components: Agilent Technologies Triple Quad 6470 LCMS/MS system with a 1290 Infinity II LC Flexible Pump (Quaternary Pump), Multisampler and Multicolumn Thermostat with 6 port valve. Agilent Masshunter Workstation Software LC/MS Data Acquisition for 6400 Series Triple Quadrupole MS with Version B.08.02 was used for compound optimization, calibration, and data acquisition.

The following solvents were employed for LC analysis. Solvent A ( $97 \%$ water and 3\% methanol $15 \mathrm{mM}$ acetic acid and $10 \mathrm{mM}$ tributylamine, $\mathrm{pH}$ of 5$)$, solvent $\mathrm{B}(15 \mathrm{mM}$ acetic acid and $10 \mathrm{mM}$ tributylamine in methanol) and washing solvent C (acetonitrile). LC system seal washing solvent (90\% water and $10 \%$ isopropanol) and needle wash solvent (75\% methanol, $25 \%$ water) were used. Solvents were purchased from the following vendors: GC-grade tributylamine 99\% (ACROS ORGANICS), LC/MS grade acetic acid Optima (Fisher Chemical), InfinityLab deactivator additive, ESI -L Low concentration Tuning mix (Agilent Technologies), LC-MS grade water, acetonitrile, methanol (Millipore) and isopropanol (Fisher Chemical).

For LC analysis, $2 \mu \mathrm{l}$ of sample was injected into an Agilent ZORBAX RRHD Extend-C18 column (2.1 $\times 150 \mathrm{~mm}, 1.8 \mu \mathrm{m}$ ) with ZORBAX Extend Fast Guards. The LC gradient profile was: flow rate: $0.25 \mathrm{ml} / \mathrm{min}$, 0-2.5 $\min , 100 \% \mathrm{~A} ; 2.5-7.5 \mathrm{~min}, 80 \% \mathrm{~A}$ and $20 \% \mathrm{~B} ; \mathrm{7} .5-13 \mathrm{~min} 55 \% \mathrm{~A}$ and $45 \% \mathrm{~B} ; 13-24 \mathrm{~min}, 1 \% \mathrm{~A}$ and $99 \% \mathrm{~B} ; 24-27 \mathrm{~min}, 1 \% \mathrm{~A}$ and $99 \% \mathrm{C} ; 27-27.5 \mathrm{~min}, 1 \% \mathrm{~A}$ and $99 \% \mathrm{C}$. Then, at $0.8 \mathrm{ml} / \mathrm{min}, 27.5-31.5 \mathrm{~min}$, $1 \% \mathrm{~A}$ and $99 \% \mathrm{C}$; at $0.6 \mathrm{ml} / \mathrm{min}, 31.5-32.25 \mathrm{~min}, 1 \% \mathrm{~A}$ and $99 \% \mathrm{C}$; at $0.4 \mathrm{ml} / \mathrm{min}, 32.25-39.9 \mathrm{~min}, 100 \%$ A; at $0.25 \mathrm{ml} / \mathrm{min}, 40 \mathrm{~min}, 100 \% \mathrm{~A}$. Column temp was maintained at $35^{\circ} \mathrm{C}$ while the samples were at $4{ }^{\circ} \mathrm{C}$.

For MS analysis, a 6470 Triple Quad MS calibrated with the Agilent ESI-L low concentration tuning mix was used. Source parameters: Gas temp $150^{\circ} \mathrm{C}$, gas flow $10 \mathrm{l} / \mathrm{min}$, nebulizer 45 psi, sheath gas temp $325^{\circ} \mathrm{C}$, sheath gas flow $12 \mathrm{l} / \mathrm{min}$, capillary -2000 V, Delta EMV -200 V. Dynamic MRM scan type was used with 0.07 min peak width and 24 min acquisition time. Delta retention time of $\pm 1 \mathrm{~min}$, fragmentor of $40 \mathrm{eV}$ and cell accelerator of $5 \mathrm{eV}$ were incorporated in the method. 
The MassHunter Metabolomics Dynamic MRM Database and Method was used for target identification. Key parameters of AJS ESI were: Gas Temp: $150{ }^{\circ} \mathrm{C}$, Gas Flow 13 l/min, Nebulizer 45 psi, Sheath Gas Temp 325 ㄷ, Sheath Gas Flow 12 I/min, Capillary 2000 V, Nozzle 500 V. Detector Delta EMV(-) 200.The QqQ data were pre-processed with an Agilent MassHunter Workstation QqQ Quantitative Analysis Software (B0700). The abundance level of each metabolite in every sample was divided by the median of all abundance levels across all samples for proper comparisons, statistical analyses, and visualization. The statistical significance test was done by a two-tailed t-test with a significance threshold level of 0.05 .

Heatmaps were generated with Morpheus, https://software.broadinstitute.org/morpheus.

\section{Statistics}

We used GraphPad Prism Version 8 software for most of our analysis. The normality was checked in all data sets and either T-test or Mann Whitney was performed for statistical analysis, statistically significant when $\mathrm{p}<0.05$. $\mathrm{qRT}-\mathrm{PCR}$ data was analyzed using multiple comparison ANOVA and considered statistically significant when $\mathrm{p}<0.05$.

\section{REFERENCES}

1. Society AC. Cancer Facts \& Figures. Atlanta: American Cancer Society;2020 2020.

2. Smit VT, Boot AJ, Smits AM, Fleuren GJ, Cornelisse CJ, Bos JL. KRAS codon 12 mutations occur very frequently in pancreatic adenocarcinomas. Nucleic Acids Res 1988;16(16):7773-82 doi 10.1093/nar/16.16.7773.

3. Almoguera C, Shibata D, Forrester K, Martin J, Arnheim N, Perucho M. Most human carcinomas of the exocrine pancreas contain mutant c-K-ras genes. Cell 1988;53(4):549-54 doi 10.1016/00928674(88)90571-5. 
4. Pour PM, Sayed S, Sayed G. Hyperplastic, preneoplastic and neoplastic lesions found in 83 human pancreases. Am J Clin Pathol 1982;77(2):137-52 doi 10.1093/ajcp/77.2.137.

5. Matsuda Y, Furukawa T, Yachida S, Nishimura M, Seki A, Nonaka K, et al. The Prevalence and Clinicopathological Characteristics of High-Grade Pancreatic Intraepithelial Neoplasia: Autopsy Study Evaluating the Entire Pancreatic Parenchyma. Pancreas 2017;46(5):658-64 doi 10.1097/MPA.0000000000000786.

6. Hingorani SR, Petricoin EF, Maitra A, Rajapakse V, King C, Jacobetz MA, et al. Preinvasive and invasive ductal pancreatic cancer and its early detection in the mouse. Cancer Cell 2003;4(6):43750.

7. Aguirre AJ, Bardeesy N, Sinha M, Lopez L, Tuveson DA, Horner J, et al. Activated Kras and Ink4a/Arf deficiency cooperate to produce metastatic pancreatic ductal adenocarcinoma. Genes Dev 2003;17(24):3112-26 doi 10.1101/gad.1158703.

8. Ying H, Dey P, Yao W, Kimmelman AC, Draetta GF, Maitra A, et al. Genetics and biology of pancreatic ductal adenocarcinoma. Genes Dev 2016;30(4):355-85 doi 10.1101/gad.275776.115.

9. De La OJ, Emerson LL, Goodman JL, Froebe SC, Illum BE, Curtis AB, et al. Notch and Kras reprogram pancreatic acinar cells to ductal intraepithelial neoplasia. Proc Natl Acad Sci U S A 2008;105(48):18907-12 doi 10.1073/pnas.0810111105.

10. Kopp JL, von Figura G, Mayes E, Liu FF, Dubois CL, Morris JPt, et al. Identification of Sox9dependent acinar-to-ductal reprogramming as the principal mechanism for initiation of pancreatic ductal adenocarcinoma. Cancer Cell 2012;22(6):737-50 doi 10.1016/j.ccr.2012.10.025.

11. Habbe N, Shi G, Meguid RA, Fendrich V, Esni F, Chen H, et al. Spontaneous induction of murine pancreatic intraepithelial neoplasia (mPanIN) by acinar cell targeting of oncogenic Kras in adult mice. Proc Natl Acad Sci U S A 2008;105(48):18913-8 doi 10.1073/pnas.0810097105.

12. von Figura G, Fukuda A, Roy N, Liku ME, Morris Iv JP, Kim GE, et al. The chromatin regulator Brg1 suppresses formation of intraductal papillary mucinous neoplasm and pancreatic ductal adenocarcinoma. Nat Cell Biol 2014;16(3):255-67 doi 10.1038/ncb2916. 
13. Roy N, Takeuchi KK, Ruggeri JM, Bailey P, Chang D, Li J, et al. PDX1 dynamically regulates pancreatic ductal adenocarcinoma initiation and maintenance. Genes Dev 2016;30(24):2669-83 doi 10.1101/gad.291021.116.

14. Morris JPt, Wang SC, Hebrok M. KRAS, Hedgehog, Wnt and the twisted developmental biology of pancreatic ductal adenocarcinoma. Nat Rev Cancer 2010;10(10):683-95 doi 10.1038/nrc2899.

15. Krah NM, Murtaugh LC. Differentiation and Inflammation: 'Best Enemies' in Gastrointestinal Carcinogenesis. Trends Cancer 2016;2(12):723-35 doi 10.1016/j.trecan.2016.11.005.

16. Krah NM, De La OJ, Swift GH, Hoang CQ, Willet SG, Chen Pan F, et al. The acinar differentiation determinant PTF1A inhibits initiation of pancreatic ductal adenocarcinoma. Elife $2015 ; 4$ doi 10.7554/eLife.07125.

17. Krah NM, Narayanan SM, Yugawa DE, Straley JA, Wright CVE, MacDonald RJ, et al. Prevention and Reversion of Pancreatic Tumorigenesis through a Differentiation-Based Mechanism. Dev Cell 2019;50(6):744-54 e4 doi 10.1016/j.devcel.2019.07.012.

18. Shi G, DiRenzo D, Qu C, Barney D, Miley D, Konieczny SF. Maintenance of acinar cell organization is critical to preventing Kras-induced acinar-ductal metaplasia. Oncogene 2013;32(15):1950-8 doi 10.1038/onc.2012.210.

19. Tuveson DA, Zhu L, Gopinathan A, Willis NA, Kachatrian L, Grochow R, et al. Mist1-KrasG12D knock-in mice develop mixed differentiation metastatic exocrine pancreatic carcinoma and hepatocellular carcinoma. Cancer Res 2006;66(1):242-7 doi 10.1158/0008-5472.CAN-05-2305.

20. von Figura G, Morris JPt, Wright CV, Hebrok M. Nr5a2 maintains acinar cell differentiation and constrains oncogenic Kras-mediated pancreatic neoplastic initiation. Gut 2014;63(4):656-64 doi 10.1136/gutjnl-2012-304287.

21. Cobo I, Martinelli P, Flandez M, Bakiri L, Zhang M, Carrillo-de-Santa-Pau E, et al. Transcriptional regulation by NR5A2 links differentiation and inflammation in the pancreas. Nature 2018;554(7693):533-7 doi 10.1038/nature25751.

22. Collins MA, Yan W, Sebolt-Leopold JS, Pasca di Magliano M. MAPK signaling is required for dedifferentiation of acinar cells and development of pancreatic intraepithelial neoplasia in mice. 
Gastroenterology 2014;146(3):822-34 e7 doi 10.1053/j.gastro.2013.11.052S0016-5085(13)017344 [pii].

23. Collisson EA, Trejo CL, Silva JM, Gu S, Korkola JE, Heiser LM, et al. A central role for RAF-->MEK->ERK signaling in the genesis of pancreatic ductal adenocarcinoma. Cancer Discov 2012;2(8):685-93 doi 2159-8290.CD-11-0347 [pii]10.1158/2159-8290.CD-11-0347.

24. Alonso-Curbelo D, Ho YJ, Burdziak C, Maag JLV, Morris JPt, Chandwani R, et al. A geneenvironment-induced epigenetic program initiates tumorigenesis. Nature 2021;590(7847):642-8 doi 10.1038/s41586-020-03147-x.

25. Clark CE, Hingorani SR, Mick R, Combs C, Tuveson DA, Vonderheide RH. Dynamics of the immune reaction to pancreatic cancer from inception to invasion. Cancer Res 2007;67(19):951827 doi 67/19/9518 [pii]10.1158/0008-5472.CAN-07-0175.

26. Mitchem JB, Brennan DJ, Knolhoff BL, Belt BA, Zhu Y, Sanford DE, et al. Targeting tumorinfiltrating macrophages decreases tumor-initiating cells, relieves immunosuppression, and improves chemotherapeutic responses. Cancer Res 2013;73(3):1128-41 doi 10.1158/00085472.CAN-12-27310008-5472.CAN-12-2731 [pii].

27. Zhang Y, Velez-Delgado A, Mathew E, Li D, Mendez FM, Flannagan K, et al. Myeloid cells are required for PD-1/PD-L1 checkpoint activation and the establishment of an immunosuppressive environment in pancreatic cancer. Gut 2017;66(1):124-36 doi 10.1136/gutjnl-2016-312078.

28. Liou GY, Doppler H, Necela B, Krishna M, Crawford HC, Raimondo M, et al. Macrophage-secreted cytokines drive pancreatic acinar-to-ductal metaplasia through NF-kappaB and MMPs. J Cell Biol 2013;202(3):563-77 doi 10.1083/jcb.201301001jcb.201301001 [pii].

29. Zhang Y, Yan W, Mathew E, Kane KT, Brannon A, 3rd, Adoumie M, et al. Epithelial-Myeloid cell crosstalk regulates acinar cell plasticity and pancreatic remodeling in mice. Elife 2017;6 doi 10.7554/eLife.27388.

30. Criscimanna A, Coudriet GM, Gittes GK, Piganelli JD, Esni F. Activated macrophages create lineage-specific microenvironments for pancreatic acinar- and beta-cell regeneration in mice. Gastroenterology 2014;147(5):1106-18 e11 doi 10.1053/j.gastro.2014.08.008. 
31. Carriere C, Young AL, Gunn JR, Longnecker DS, Korc M. Acute pancreatitis markedly accelerates pancreatic cancer progression in mice expressing oncogenic Kras. Biochem Biophys Res Commun 2009;382(3):561-5 doi 10.1016/j.bbrc.2009.03.068.

32. Guerra C, Collado M, Navas C, Schuhmacher AJ, Hernandez-Porras I, Canamero M, et al. Pancreatitis-induced inflammation contributes to pancreatic cancer by inhibiting oncogene-induced senescence. Cancer Cell 2011;19(6):728-39 doi 10.1016/j.ccr.2011.05.011.

33. Collins MA, Bednar F, Zhang Y, Brisset JC, Galban S, Galban CJ, et al. Oncogenic Kras is required for both the initiation and maintenance of pancreatic cancer in mice. J Clin Invest 2012;122(2):63953 doi 10.1172/JCI5922759227 [pii].

34. Ying H, Kimmelman AC, Lyssiotis CA, Hua S, Chu GC, Fletcher-Sananikone E, et al. Oncogenic Kras maintains pancreatic tumors through regulation of anabolic glucose metabolism. Cell 2012;149(3):656-70 doi 10.1016/j.cell.2012.01.058.

35. Wen HJ, Gao S, Wang Y, Ray M, Magnuson MA, Wright CVE, et al. Myeloid Cell-Derived HB-EGF Drives Tissue Recovery After Pancreatitis. Cell Mol Gastroenterol Hepatol 2019;8(2):173-92 doi 10.1016/j.jcmgh.2019.05.006.

36. Ardito CM, Gruner BM, Takeuchi KK, Lubeseder-Martellato C, Teichmann N, Mazur PK, et al. EGF receptor is required for KRAS-induced pancreatic tumorigenesis. Cancer Cell 2012;22(3):304-17 doi 10.1016/j.ccr.2012.07.024S1535-6108(12)00337-6 [pii].

37. Navas C, Hernandez-Porras I, Schuhmacher AJ, Sibilia M, Guerra C, Barbacid M. EGF receptor signaling is essential for k-ras oncogene-driven pancreatic ductal adenocarcinoma. Cancer Cell 2012;22(3):318-30 doi 10.1016/j.ccr.2012.08.001S1535-6108(12)00338-8 [pii].

38. Zhu Y, Herndon JM, Sojka DK, Kim KW, Knolhoff BL, Zuo C, et al. Tissue-Resident Macrophages in Pancreatic Ductal Adenocarcinoma Originate from Embryonic Hematopoiesis and Promote Tumor Progression. Immunity 2017;47(3):597 doi 10.1016/j.immuni.2017.08.018.

39. Monti P, Leone BE, Marchesi F, Balzano G, Zerbi A, Scaltrini F, et al. The CC chemokine MCP1/CCL2 in pancreatic cancer progression: regulation of expression and potential mechanisms of antimalignant activity. Cancer Res 2003;63(21):7451-61. 
40. Sanford DE, Belt BA, Panni RZ, Mayer A, Deshpande AD, Carpenter D, et al. Inflammatory monocyte mobilization decreases patient survival in pancreatic cancer: a role for targeting the CCL2/CCR2 axis. Clin Cancer Res 2013;19(13):3404-15 doi 10.1158/1078-0432.CCR-13-0525.

41. Gurczynski SJ, Nathani N, Warheit-Niemi HI, Hult EM, Podsiad A, Deng J, et al. CCR2 mediates increased susceptibility to post-H1N1 bacterial pneumonia by limiting dendritic cell induction of IL17. Mucosal Immunol 2019;12(2):518-30 doi 10.1038/s41385-018-0106-4.

42. Storz P. Acinar cell plasticity and development of pancreatic ductal adenocarcinoma. Nat Rev Gastroenterol Hepatol 2017 doi 10.1038/nrgastro.2017.12.

43. Yu H, Kortylewski M, Pardoll D. Crosstalk between cancer and immune cells: role of STAT3 in the tumour microenvironment. Nat Rev Immunol 2007;7(1):41-51 doi 10.1038/nri1995.

44. Kemp SB, Carpenter ES, Steele NG, Donahue KL, Nwosu ZC, Pacheco A, et al. Apolipoprotein E promotes immune suppression in pancreatic cancer through NF-kB-mediated production of CXCL1. Cancer Res 2021 doi 10.1158/0008-5472.Can-20-3929.

45. Katzenelenbogen Y, Sheban F, Yalin A, Yofe I, Svetlichnyy D, Jaitin DA, et al. Coupled scRNASeq and Intracellular Protein Activity Reveal an Immunosuppressive Role of TREM2 in Cancer. Cell 2020;182(4):872-85 e19 doi 10.1016/j.cell.2020.06.032.

46. Kemp SB, Steele NG, Carpenter ES, Donahue KL, Bushnell GG, Morris AH, et al. Pancreatic cancer is marked by complement-high blood monocytes and tumor-associated macrophages. Life Sci Alliance 2021;4(6) doi 10.26508/lsa.202000935.

47. Ramilowski JA, Goldberg T, Harshbarger J, Kloppmann E, Lizio M, Satagopam VP, et al. A draft network of ligand-receptor-mediated multicellular signalling in human. Nat Commun 2015;6:7866 doi $10.1038 /$ ncomms8866.

48. Steele NG, Carpenter ES, Kemp SB, Sirihorachai VR, The S, Delrosario L, et al. Multimodal mapping of the tumor and peripheral blood immune landscape in human pancreatic cancer. Nature Cancer 2020;1(11):1097-112 doi 10.1038/s43018-020-00121-4. 
49. Collins MA, Brisset JC, Zhang Y, Bednar F, Pierre J, Heist KA, et al. Metastatic pancreatic cancer is dependent on oncogenic Kras in mice. PLoS One 2012;7(12):e49707 doi 10.1371/journal.pone.0049707

PONE-D-12-09212 [pii].

50. Mathew E, Collins MA, Fernandez-Barrena MG, Holtz AM, Yan W, Hogan JO, et al. The transcription factor GLI1 modulates the inflammatory response during pancreatic tissue remodeling. J Biol Chem 2014;289(40):27727-43 doi 10.1074/jbc.M114.556563.

51. Colegio OR, Chu NQ, Szabo AL, Chu T, Rhebergen AM, Jairam V, et al. Functional polarization of tumour-associated macrophages by tumour-derived lactic acid. Nature 2014;513(7519):559-63 doi 10.1038/nature13490.

52. Wu JY, Huang TW, Hsieh YT, Wang YF, Yen CC, Lee GL, et al. Cancer-Derived Succinate Promotes Macrophage Polarization and Cancer Metastasis via Succinate Receptor. Mol Cell 2020;77(2):213-27 e5 doi 10.1016/j.molcel.2019.10.023.

53. Saxton RA, Sabatini DM. mTOR Signaling in Growth, Metabolism, and Disease. Cell 2017;169(2):361-71 doi 10.1016/j.cell.2017.03.035.

54. Hooftman A, O'Neill LAJ. The Immunomodulatory Potential of the Metabolite Itaconate. Trends Immunol 2019;40(8):687-98 doi 10.1016/j.it.2019.05.007.

55. Becker LM, O'Connell JT, Vo AP, Cain MP, Tampe D, Bizarro L, et al. Epigenetic Reprogramming of Cancer-Associated Fibroblasts Deregulates Glucose Metabolism and Facilitates Progression of Breast Cancer. Cell Rep 2020;31(9):107701 doi 10.1016/j.celrep.2020.107701.

56. Biankin AV, Waddell N, Kassahn KS, Gingras MC, Muthuswamy LB, Johns AL, et al. Pancreatic cancer genomes reveal aberrations in axon guidance pathway genes. Nature 2012;491(7424):399405 doi 10.1038/nature11547.

57. Kanda M, Matthaei H, Wu J, Hong SM, Yu J, Borges M, et al. Presence of somatic mutations in most early-stage pancreatic intraepithelial neoplasia. Gastroenterology 2012;142(4):730-3 e9 doi 10.1053/j.gastro.2011.12.042. 
58. Zhang Y, Yan W, Collins MA, Bednar F, Rakshit S, Zetter BR, et al. Interleukin-6 is required for pancreatic cancer progression by promoting MAPK signaling activation and oxidative stress resistance. Cancer Res 2013;73(20):6359-74 doi 10.1158/0008-5472.CAN-13-1558-T00085472.CAN-13-1558-T [pii].

59. Fukuda A, Wang SC, Morris JPt, Folias AE, Liou A, Kim GE, et al. Stat3 and MMP7 contribute to pancreatic ductal adenocarcinoma initiation and progression. Cancer Cell 2011;19(4):441-55 doi 10.1016/j.ccr.2011.03.002S1535-6108(11)00091-2 [pii].

60. Lesina M, Kurkowski MU, Ludes K, Rose-John S, Treiber M, Kloppel G, et al. Stat3/Socs3 activation by IL-6 transsignaling promotes progression of pancreatic intraepithelial neoplasia and development of pancreatic cancer. Cancer Cell 2011;19(4):456-69 doi 10.1016/j.ccr.2011.03.009S1535-6108(11)00119-X [pii].

61. Djurec M, Grana O, Lee A, Troule K, Espinet E, Cabras L, et al. Saa3 is a key mediator of the protumorigenic properties of cancer-associated fibroblasts in pancreatic tumors. Proc Natl Acad Sci U S A 2018;115(6):E1147-E56 doi 10.1073/pnas.1717802115.

62. Li J, Byrne KT, Yan F, Yamazoe T, Chen Z, Baslan T, et al. Tumor Cell-Intrinsic Factors Underlie Heterogeneity of Immune Cell Infiltration and Response to Immunotherapy. Immunity 2018;49(1):178-93 e7 doi 10.1016/j.immuni.2018.06.006.

63. Feig C, Jones JO, Kraman M, Wells RJ, Deonarine A, Chan DS, et al. Targeting CXCL12 from FAP-expressing carcinoma-associated fibroblasts synergizes with anti-PD-L1 immunotherapy in pancreatic cancer. Proc Natl Acad Sci U S A 2013;110(50):20212-7 doi 10.1073/pnas.1320318110.

64. Ozdemir BC, Pentcheva-Hoang T, Carstens JL, Zheng X, Wu CC, Simpson TR, et al. Depletion of carcinoma-associated fibroblasts and fibrosis induces immunosuppression and accelerates pancreas cancer with reduced survival. Cancer Cell 2014;25(6):719-34 doi 10.1016/j.ccr.2014.04.005.

65. Garcia PE, Adoumie M, Kim EC, Zhang Y, Scales MK, El-Tawil YS, et al. Differential Contribution of Pancreatic Fibroblast Subsets to the Pancreatic Cancer Stroma. Cell Mol Gastroenterol Hepatol 2020;10(3):581-99 doi 10.1016/j.jcmgh.2020.05.004. 
66. Helms EJ, Berry MW, Chaw RC, DuFort CC, Sun D, Onate MK, et al. Mesenchymal Lineage Heterogeneity Underlies Non-Redundant Functions of Pancreatic Cancer-Associated Fibroblasts. bioRxiv 2021:2021.05.01.442252 doi 10.1101/2021.05.01.442252.

67. Biffi G, Oni TE, Spielman B, Hao Y, Elyada E, Park Y, et al. IL1-Induced JAK/STAT Signaling Is Antagonized by TGFbeta to Shape CAF Heterogeneity in Pancreatic Ductal Adenocarcinoma. Cancer Discov 2019;9(2):282-301 doi 10.1158/2159-8290.CD-18-0710.

68. Elyada E, Bolisetty M, Laise P, Flynn WF, Courtois ET, Burkhart RA, et al. Cross-Species SingleCell Analysis of Pancreatic Ductal Adenocarcinoma Reveals Antigen-Presenting CancerAssociated Fibroblasts. Cancer Discov 2019;9(8):1102-23 doi 10.1158/2159-8290.CD-19-0094.

69. Ohlund D, Handly-Santana A, Biffi G, Elyada E, Almeida AS, Ponz-Sarvise M, et al. Distinct populations of inflammatory fibroblasts and myofibroblasts in pancreatic cancer. J Exp Med 2017 doi 10.1084/jem.20162024.

70. Ischenko I, D’Amico S, Rao M, Li J, Hayman MJ, Powers S, et al. KRAS drives immune evasion in a genetic model of pancreatic cancer. Nature Communications 2021;12(1):1482 doi 10.1038/s41467-021-21736-w.

71. Kortlever RM, Sodir NM, Wilson CH, Burkhart DL, Pellegrinet L, Brown Swigart L, et al. Myc Cooperates with Ras by Programming Inflammation and Immune Suppression. Cell 2017;171(6):1301-15 e14 doi 10.1016/j.cell.2017.11.013.

72. Zhu Y, Knolhoff BL, Meyer MA, Nywening TM, West BL, Luo J, et al. CSF1/CSF1R Blockade Reprograms Tumor-Infiltrating Macrophages and Improves Response to T-cell Checkpoint Immunotherapy in Pancreatic Cancer Models. Cancer Res 2014 doi 0008-5472.CAN-13-3723 [pii]10.1158/0008-5472.CAN-13-3723.

73. Beatty GL, Chiorean EG, Fishman MP, Saboury B, Teitelbaum UR, Sun W, et al. CD40 agonists alter tumor stroma and show efficacy against pancreatic carcinoma in mice and humans. Science 2011;331(6024):1612-6 doi 10.1126/science.1198443331/6024/1612 [pii].

74. O'Hara MH, O'Reilly EM, Wolff RA, Wainberg ZA, Ko AH, Rahma OE, et al. Gemcitabine (Gem) and nab-paclitaxel (NP) \pm nivolumab (nivo) \pm CD40 agonistic monoclonal antibody APX005M 
(sotigalimab), in patients (Pts) with untreated metastatic pancreatic adenocarcinoma (mPDAC): Phase (Ph) 2 final results. Journal of Clinical Oncology 2021;39(15_suppl):4019- doi 10.1200/JCO.2021.39.15_suppl.4019.

75. Nowicka M, Krieg C, Crowell HL, Weber LM, Hartmann FJ, Guglietta S, et al. CyTOF workflow: differential discovery in high-throughput high-dimensional cytometry datasets. F1000Res 2017;6:748 doi 10.12688/f1000research.11622.3.

76. Stuart T, Butler A, Hoffman P, Hafemeister C, Papalexi E, Mauck WM, 3rd, et al. Comprehensive Integration of Single-Cell Data. Cell 2019;177(7):1888-902 e21 doi 10.1016/j.cell.2019.05.031.

77. Butler A, Hoffman P, Smibert P, Papalexi E, Satija R. Integrating single-cell transcriptomic data across different conditions, technologies, and species. Nat Biotechnol 2018;36(5):411-20 doi 10.1038/nbt.4096.

78. Shannon P, Markiel A, Ozier O, Baliga NS, Wang JT, Ramage D, et al. Cytoscape: a software environment for integrated models of biomolecular interaction networks. Genome Res 2003;13(11):2498-504 doi 10.1101/gr.1239303. 
bioRxiv preprint doi: https://doi.org/10.1101/2021.08.26.457660; this version posted August 27, 2021. The copyright holder for this preprint (which was not certified by peer review) is the author/funder. All rights reserved. No reuse allowed without permission.

A
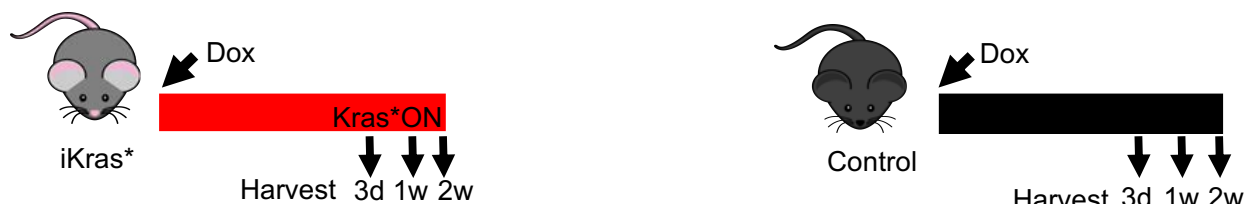

Harvest 3d 1w 2w

B

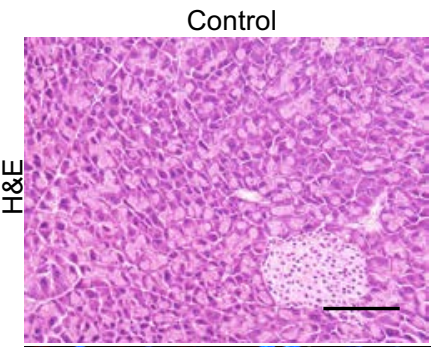

Kras* $^{*} \mathrm{~d}$ ON $\mathrm{Kras}^{*} 1 \mathrm{w}$ ON

$\mathrm{Kras}^{*} 2 \mathrm{w}$ ON

C
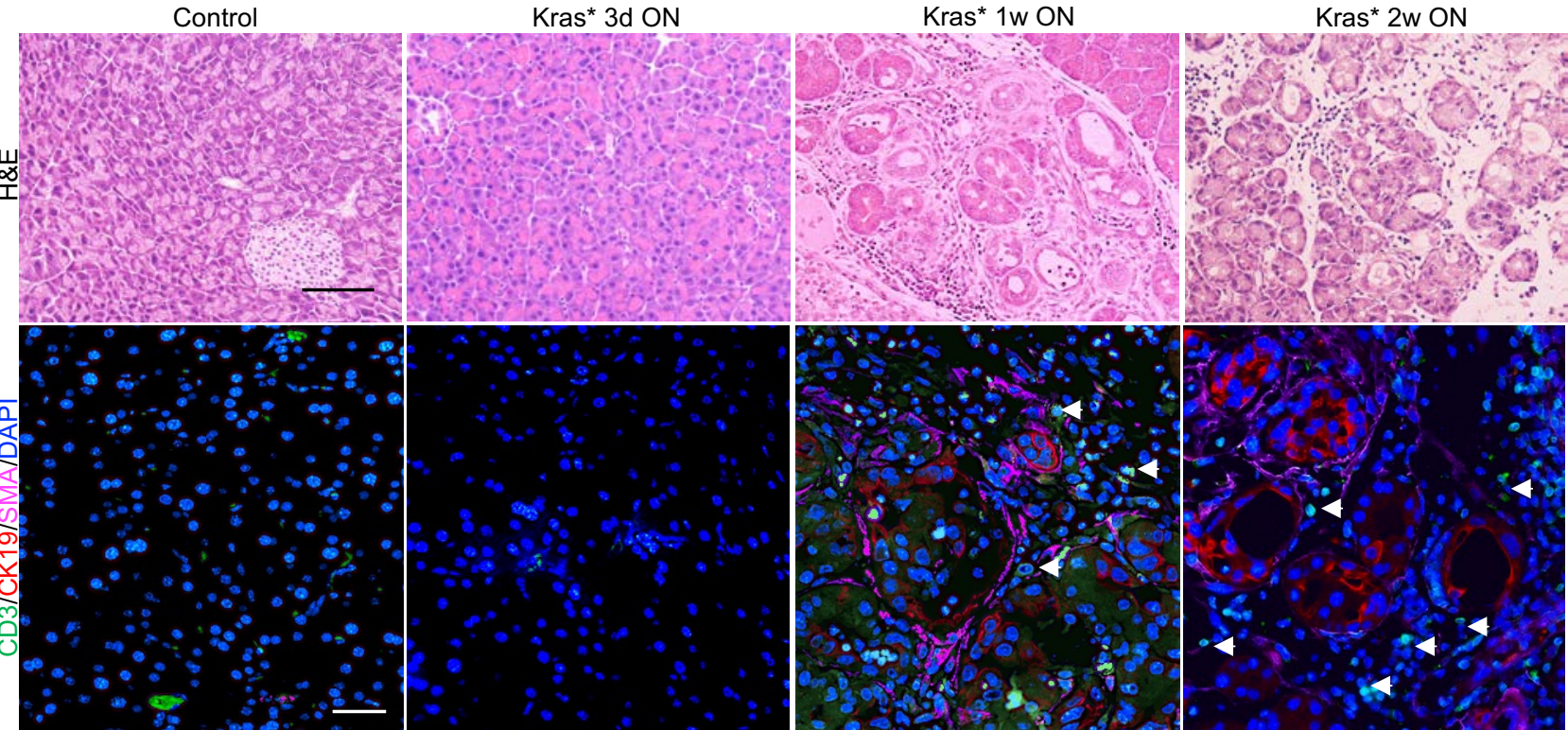

D

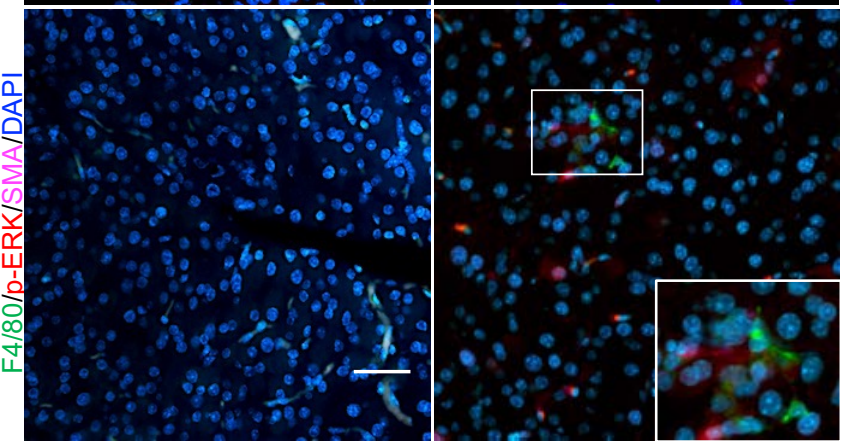

$\mathbf{E}$

$\mathrm{Kras}^{*} 1 \mathrm{w}$ ON

F4/80

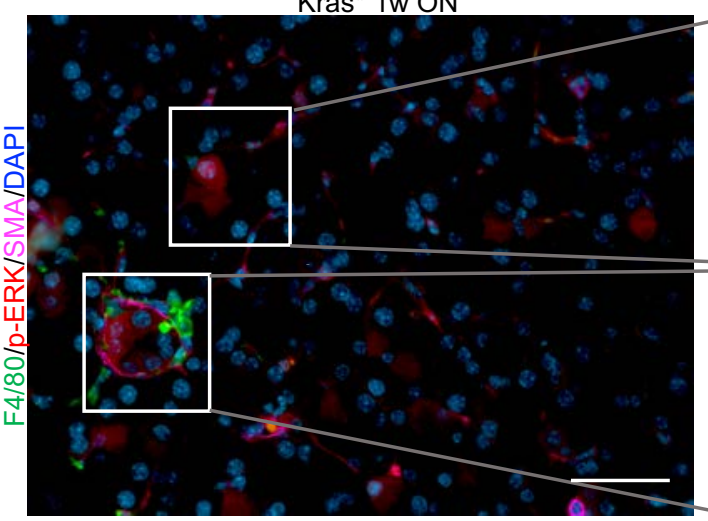

F

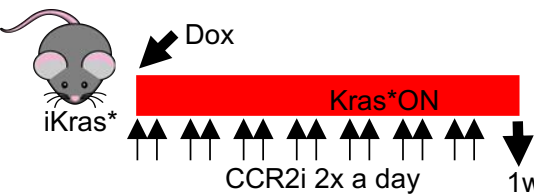

1w Harvest

H
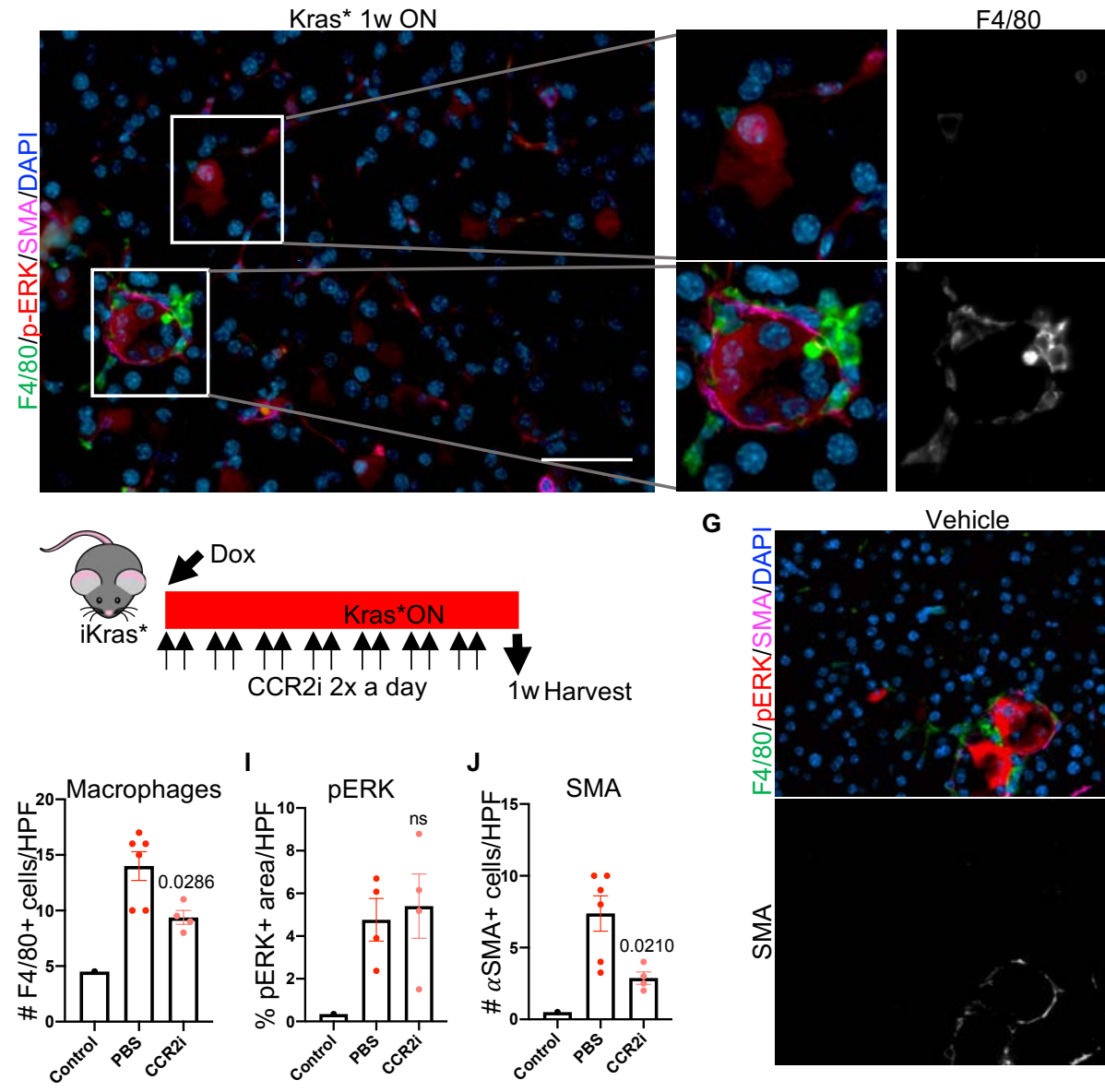

aSMA

DAPI
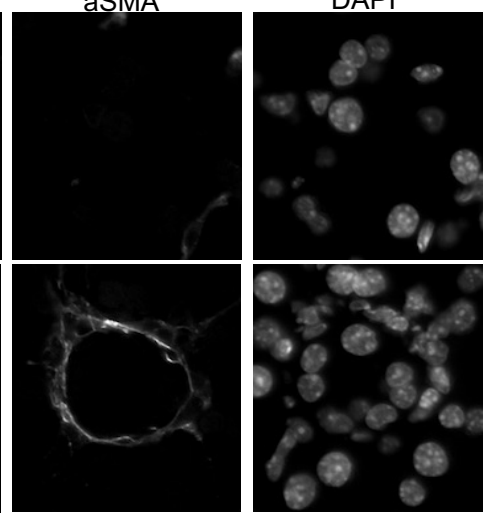

Vehicle

CCR2i
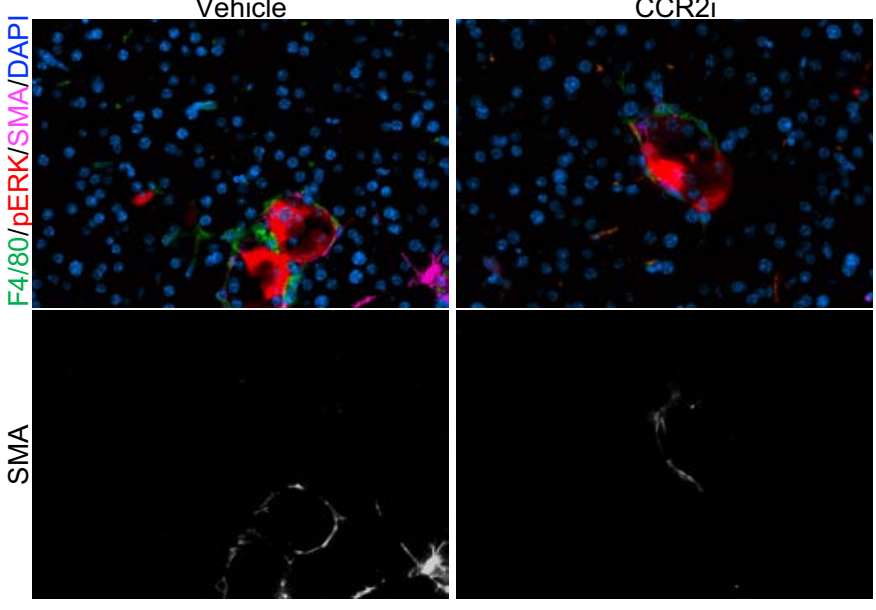
Figure 1. Oncogenic Kras drives the recruitment of myeloid cells prior to acinar transdifferentiation.

A, Experimental design. Control (lacking either the Kras or Ptf1a ${ }^{\text {Cre }}$ allele) and iKras ${ }^{*}$ mice were given Doxycycline (DOX) chow to activate oncogenic Kras (Kras*) in the iKras* mice and pancreata were harvested either at 3 days (3d), 1 week (1w) or 2 weeks $(2 w) . N=3-5$ mice per group. B, Representative images of Hematoxylin and Eosin (H\&E) staining of control and iKras* pancreata at the indicated time points. $\mathrm{N}=3-5$ mice per group. Scale bar $100 \mu \mathrm{m}$. C, Representative images of CD3 (green), CK19 (red) and SMA (magenta) co-immunofluorescent staining in control and iKras* pancreata at the indicated time points, arrows pointing to $\mathrm{CD}^{+} \mathrm{T}$ cells. $\mathrm{N}=3$ mice per group. Scale bar $50 \mu \mathrm{m}$. D, Representative images of F4/80 (green), pERK (red) and SMA (magenta) co-immunofluorescent staining in control and iKras* pancreata at the indicated time points. $\mathrm{N}=3$ mice per group. Scale bar 50 $\mu \mathrm{m}$. E, Representative images of F4/80 (green), p-ERK (red) and SMA (magenta) coimmunofluorescence staining of an iKras* pancreas after activating Kras* for 1 week. Regions with high expression of $\mathrm{p}$-ERK are enlarged and single channel images are included. $\mathrm{N}=3$ mice. Scale bar $50 \mu \mathrm{m}$. F, Experimental design. iKras* mice were given DOX to turn ON Kras* and were treated at the same time with a CCR2 inhibitor (CCR2i) or PBS twice a day for a week. $\mathrm{N}=6$ mice per group. G, Representative images of F4/80 (green), p-ERK (red) and SMA (magenta) co-immunofluorescent staining. Bottom row: single channel images for SMA. Scale bar $50 \mu \mathrm{m}$. Quantification of $\mathrm{F} 4 / 80^{+}$macrophages $(\mathrm{H}), \mathrm{p}$-ERK ${ }^{+}$ cells (I) and $\mathrm{SMA}^{+}$activated fibroblasts ( $\mathrm{J}$ ) for the experiment described in $\mathrm{F}$.

Data is measured as number of cells per high power field (HPF) (400X for F4/80 and SMA, 200X for p-ERK), and expressed as mean \pm SEM. The statistic difference between PBS and CCR2i was determined by two-tailed Mann-Whitney or unpaired $t-$ test. See also Figure $\mathrm{S} 1$ 
A
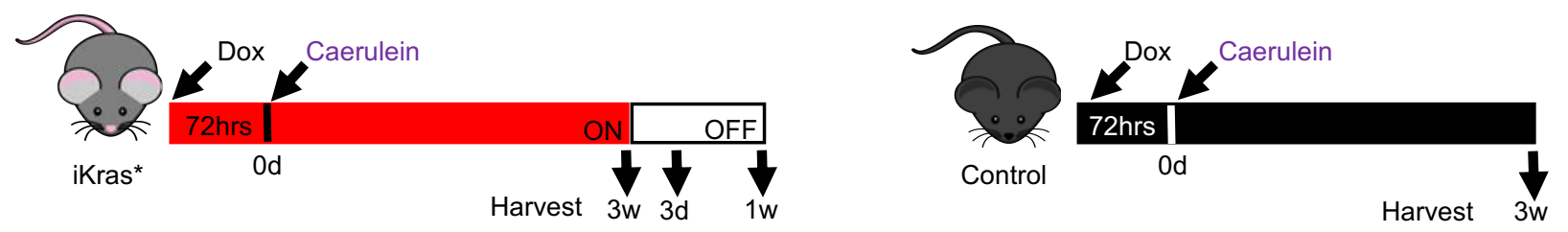

B
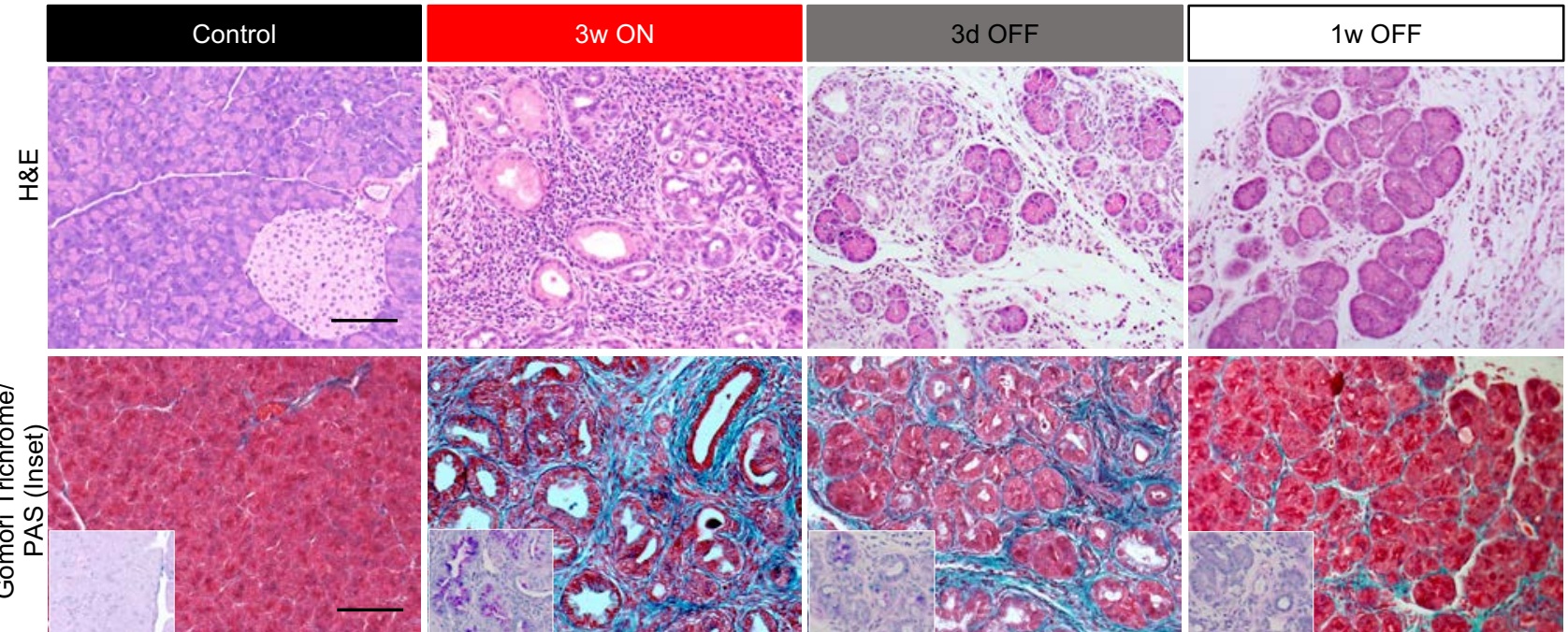

C
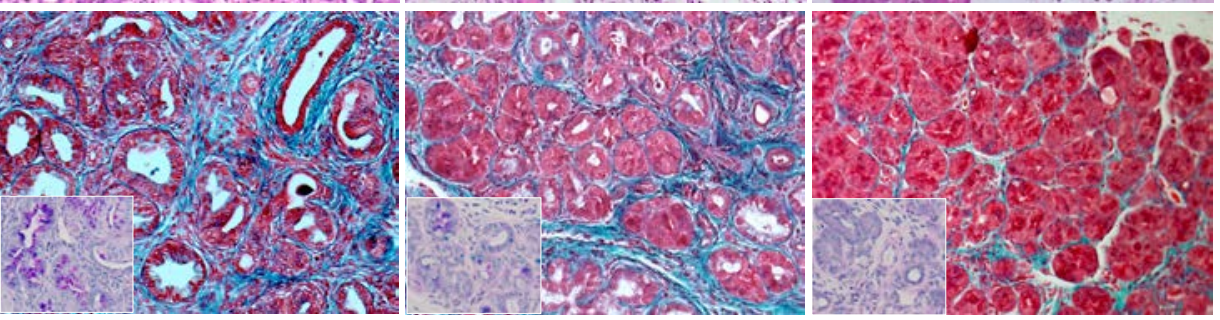

D
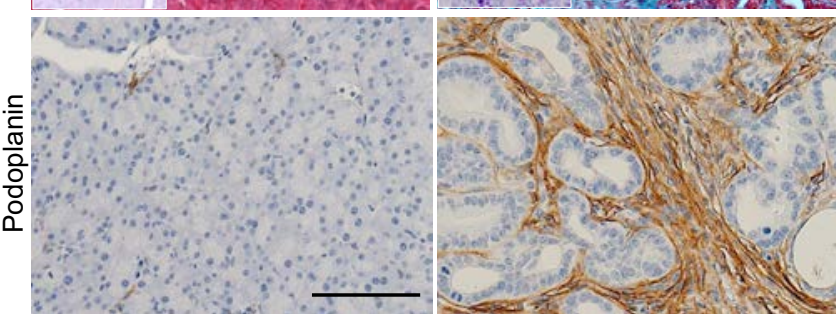

E
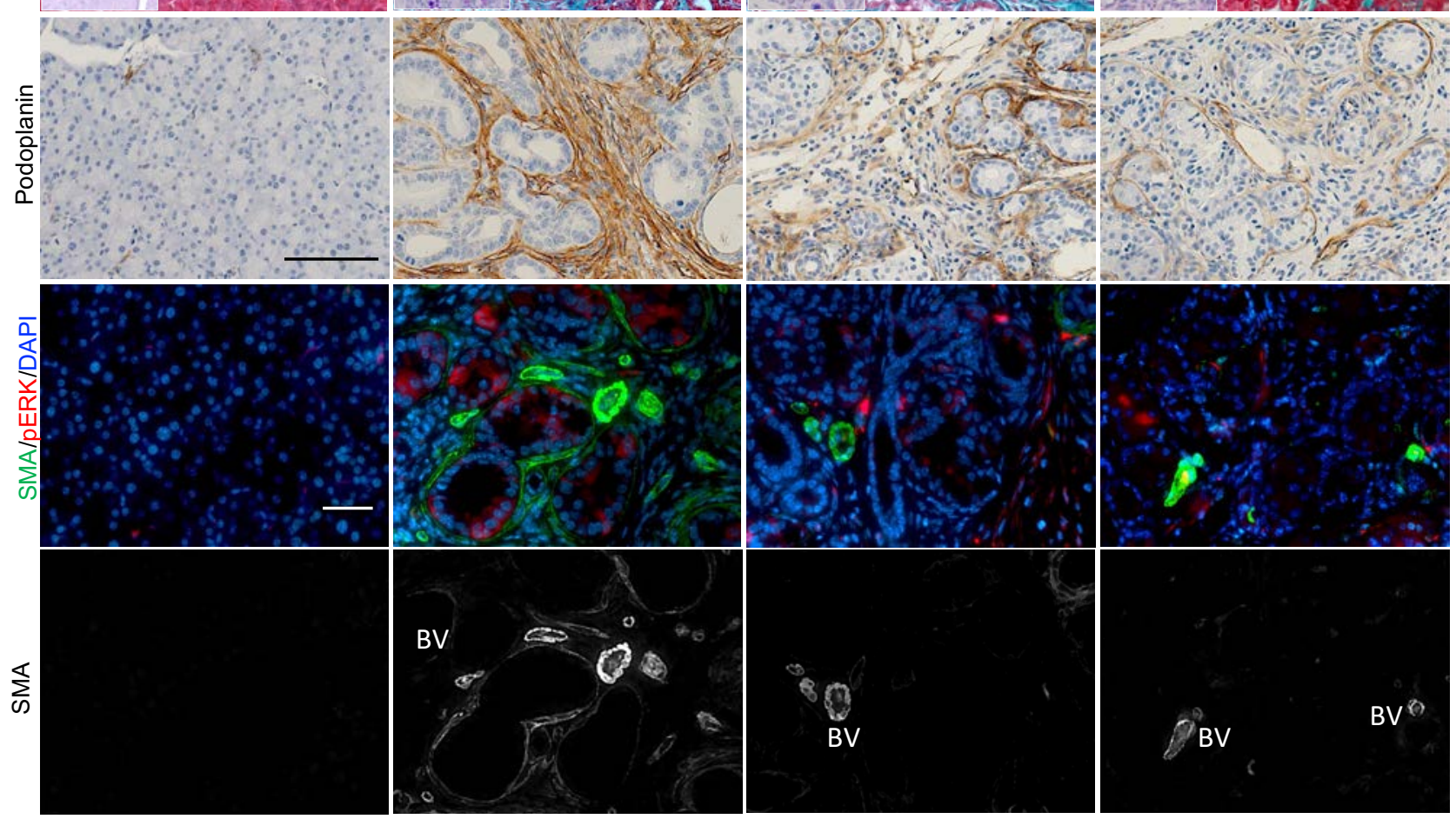

F

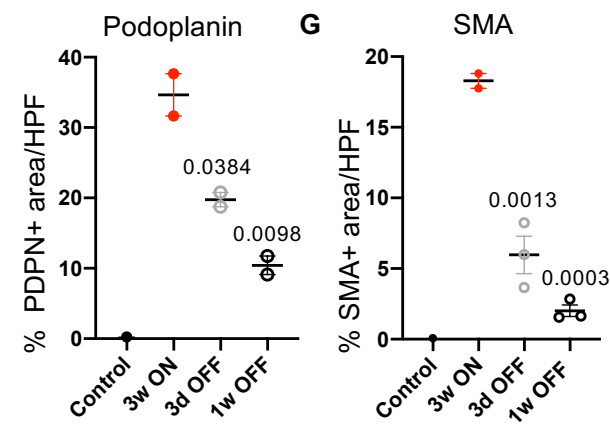



(which was not certified by peer review) is the author/funder. All rights reserved. No reuse allowed without permission.

Figure 2. Sustained expression of Kras is required to maintain PanIN and fibrosis.

A, Experimental design. Wild type control and iKras* mice were given DOX chow to activate Kras* followed by induction of acute pancreatitis. Mice were then left on DOX chow for three weeks, at which point pancreata were harvested (3w ON) or the DOX chow was removed and the pancreata were harvested after 3 days or 1 week (labeled $3 \mathrm{~d}$ OFF or $1 \mathrm{w}$ OFF respectively). $\mathrm{N}=8$ mice per group. $\mathrm{B}$, Representative images of $\mathrm{H} \& \mathrm{E}$ staining of control and iKras* pancreata at the indicated time points, N=8 mice per group. Scale bar $100 \mu \mathrm{m}$. C, Representative images of Gomori Trichrome and Periodic Acid-Schiff Stain (PAS; inset) of control or iKras* pancreata at the indicated time points, N=2-3 mice per group. Scale bar $100 \mu \mathrm{m}$. D, Immunostaining for Podoplanin (Scale bar $100 \mu \mathrm{m}$ ). E, Immunofluorescent staining for SMA (green) and p-ERK (red). Scale bar $50 \mu \mathrm{m}$. N=2-3 mice per group. Quantification of Podoplanin (F) and SMA staining (G), shown as mean \pm SEM. Statistical differences were determined by multiple ANOVA, all compared to 3w ON group. 
bioRxiv preprint doi: https://doi.org/10.1101/2021.08.26.457660; this version posted August 27, 2021. The copyright holder for this preprint (which was not certified by peer review) is the author/funder. All rights reserved. No reuse allowed without permission.

A
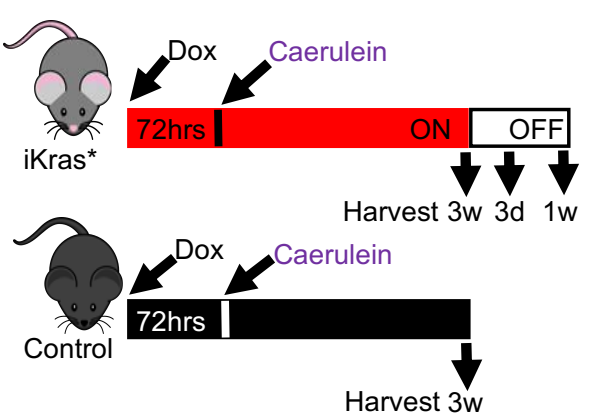

C

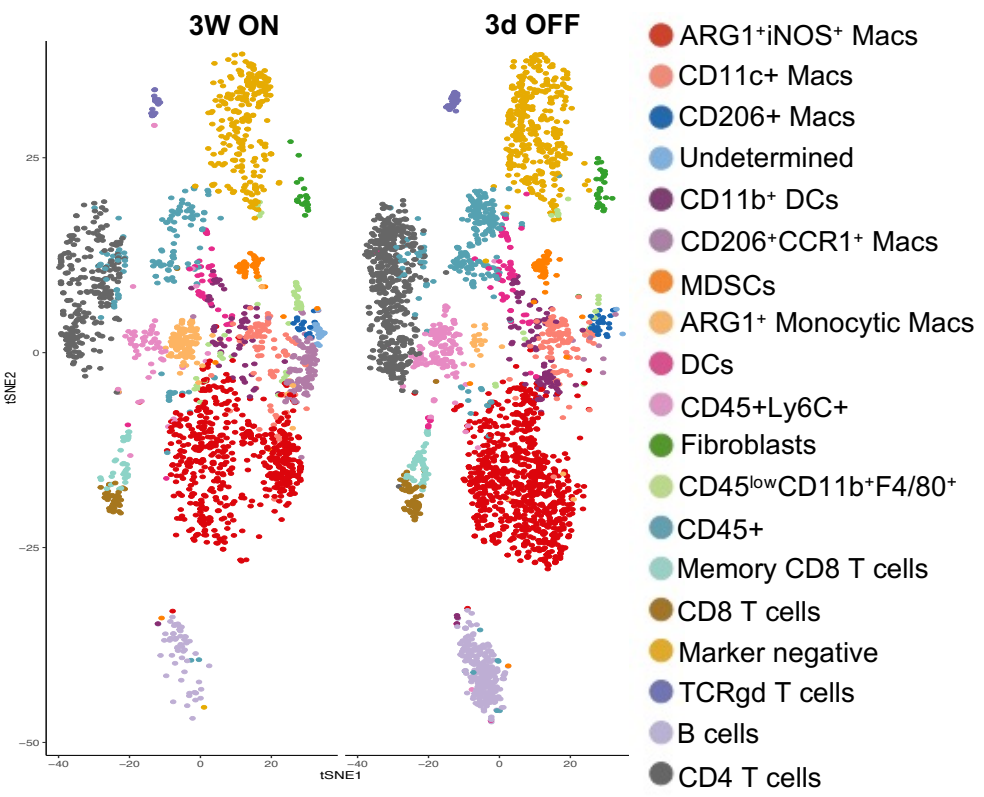

$\mathrm{CD}^{2} \mathrm{C}^{+} \mathrm{CD11b^{+ }} \quad \mathrm{CD} 45^{+} \mathrm{CD} 11 \mathrm{~b}+\mathrm{F} 4 / 80^{+}$

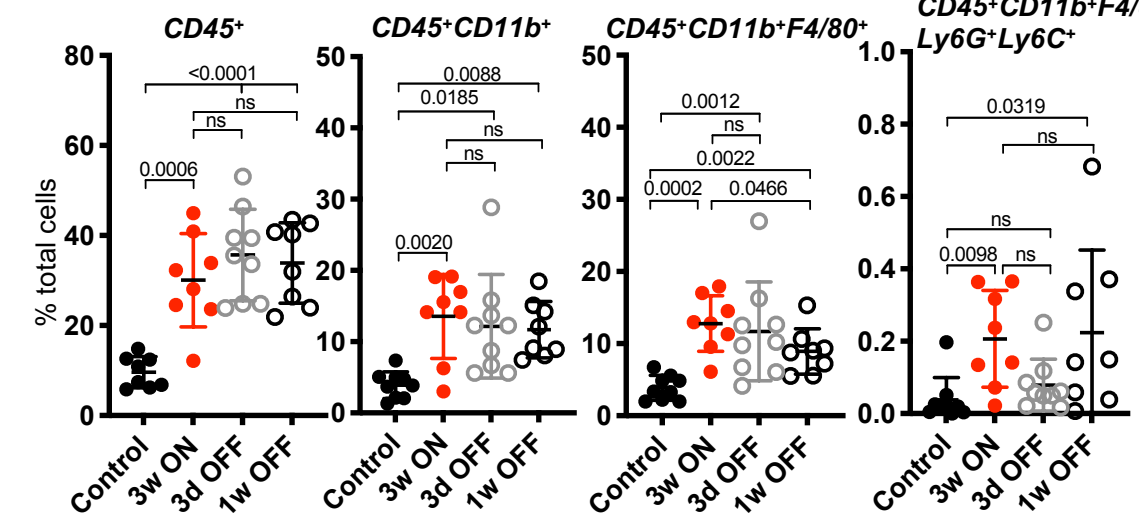

$C D 45^{+} C D 11 b^{+} F 4 / 80$
D

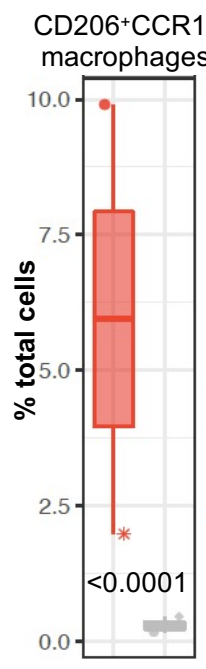

Macrophages $=\mathrm{CD} 45^{+} \mathrm{CD} 11 \mathrm{~b}+\mathrm{F} 4 / 80^{+}$ MDSCs $=$ CD45+CD11b+F4/80-Ly6C+ Ly6G +
$\mathrm{ARG}+\mathrm{iNOS}^{+} \quad \mathrm{CD}^{+} 1 \mathrm{c}^{+}$ macrophages macrophages

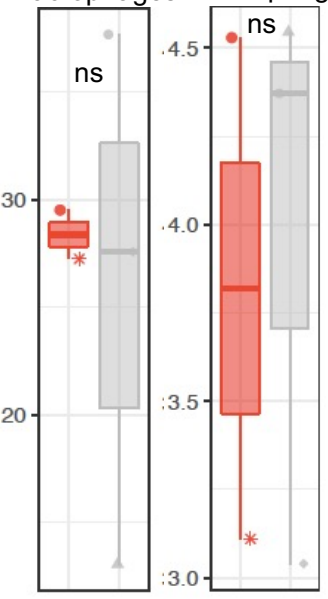

condition 宙 On
$E$
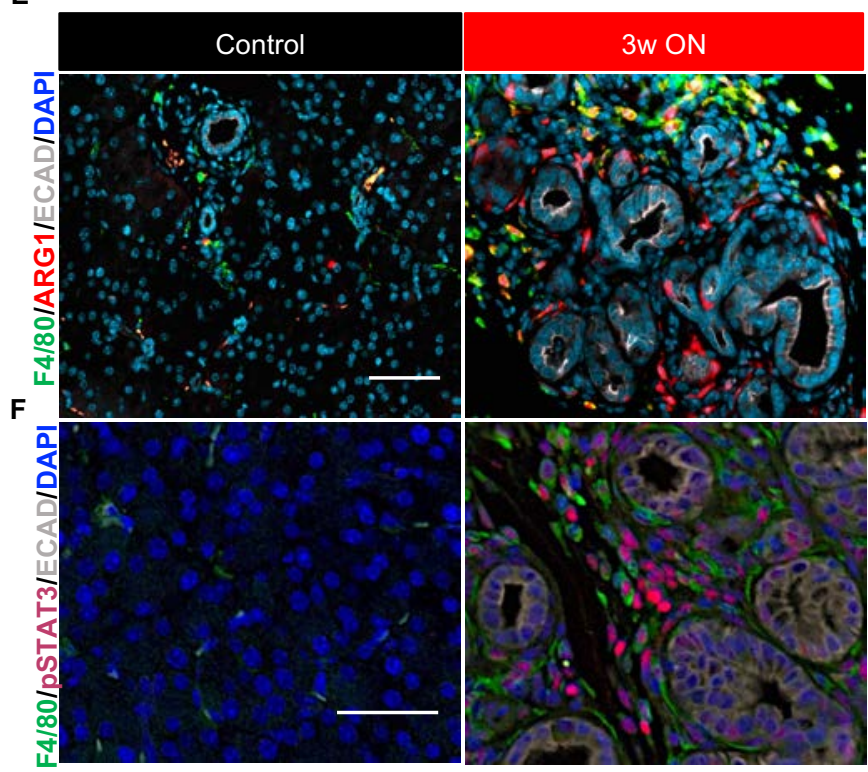

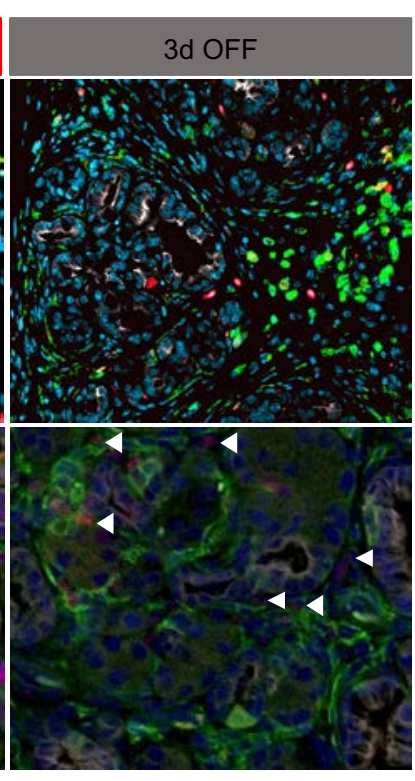

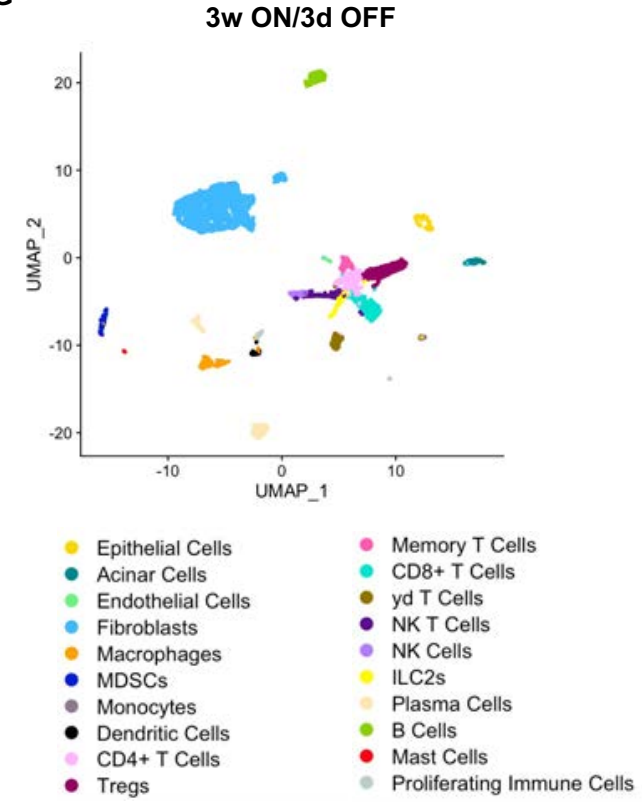

H

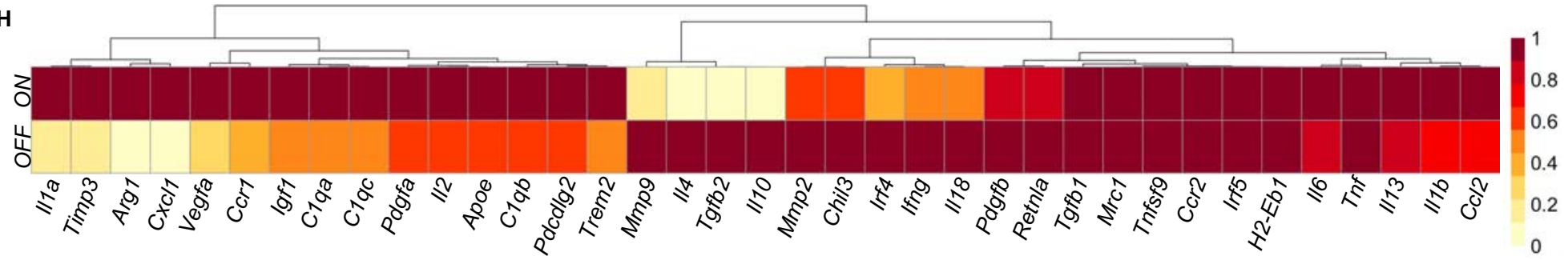


Figure 3. Oncogenic Kras regulates myeloid cell polarization status.

A, Experimental Design. N=8-9 mice per group. B, Quantification of flow cytometry results. Immune cell populations are expressed as percentage of total cells in control or iKras* pancreata at the indicated time points, shown as mean \pm SD. Statistical analysis by multiple comparison ANOVA and multiple comparison Kruskal Wallis. C, CyTOF analysis of iKras* pancreata visualized by tSNE plot for $3 \mathrm{w}$ ON and 3d OFF timepoints. Nineteen distinct cell clusters were identified by FLowSOM using 18 markers and 1061 randomly selected cells per group. N=2-3 mice per group. D, Quantification of specific cell populations, as indicated. The statistical analysis by Wrapper function. E, Immunostaining for F4/80 (green), Arg1 (red), and Ecad (White) in control and iKras* pancreata at the indicated time points. $\mathrm{N}=3$ mice per group. Scale bar $50 \mu \mathrm{m}$. $\mathbf{F}$, Immunostianing for of F4/80 (green), pSTAT3 (Magenta), and Ecad (White). N=3 mice per group. Scale bar $50 \mu \mathrm{m}$. G, Uniform and manifold approximation and projection (UMAP) visualization of single-cell RNA-sequencing data showing unsupervised clustering of cells from combined iKras* pancreatic samples ( $3 w \mathrm{ON}, \mathrm{N}=2$ and $3 \mathrm{~d}$ OFF, N=3). Each color represents a distinct cellular cluster. $\mathbf{H}$, Heatmap showing the averaged single-cell RNA sequencing expression data (relative to the highest expressor) for genes in macrophages selected from a curated list of macrophage polarization and functional markers. See also Figure S2, Figure S3 
bioRxiv preprint doi: https://doi.org/10.1101/2021.08.26.457660; this version posted August 27, 2021. The copyright holder for this preprint

A

B

D
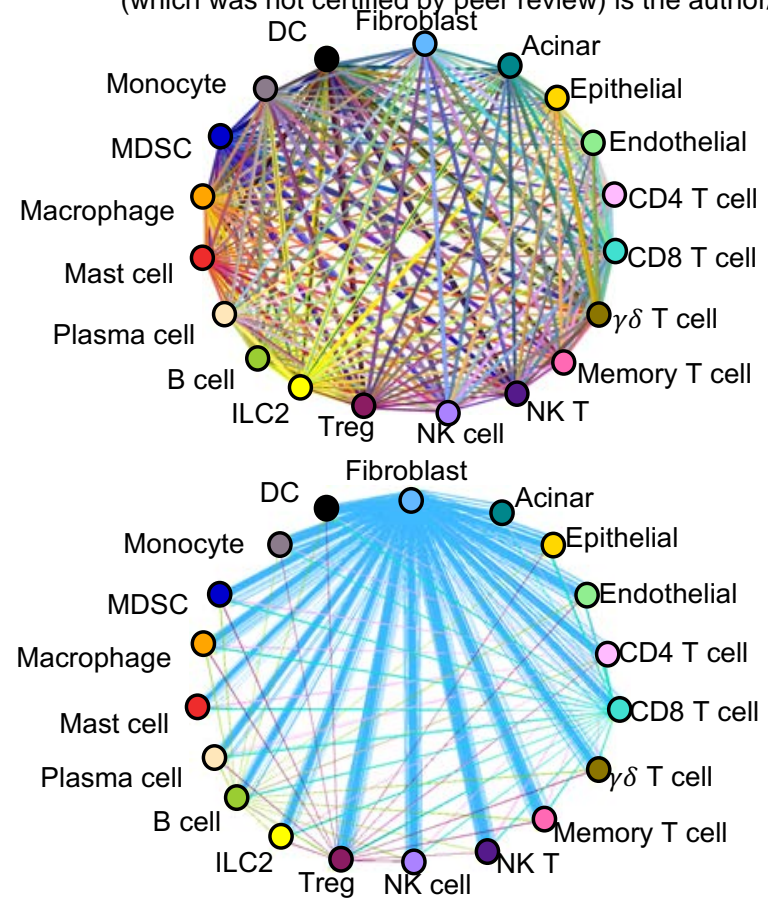

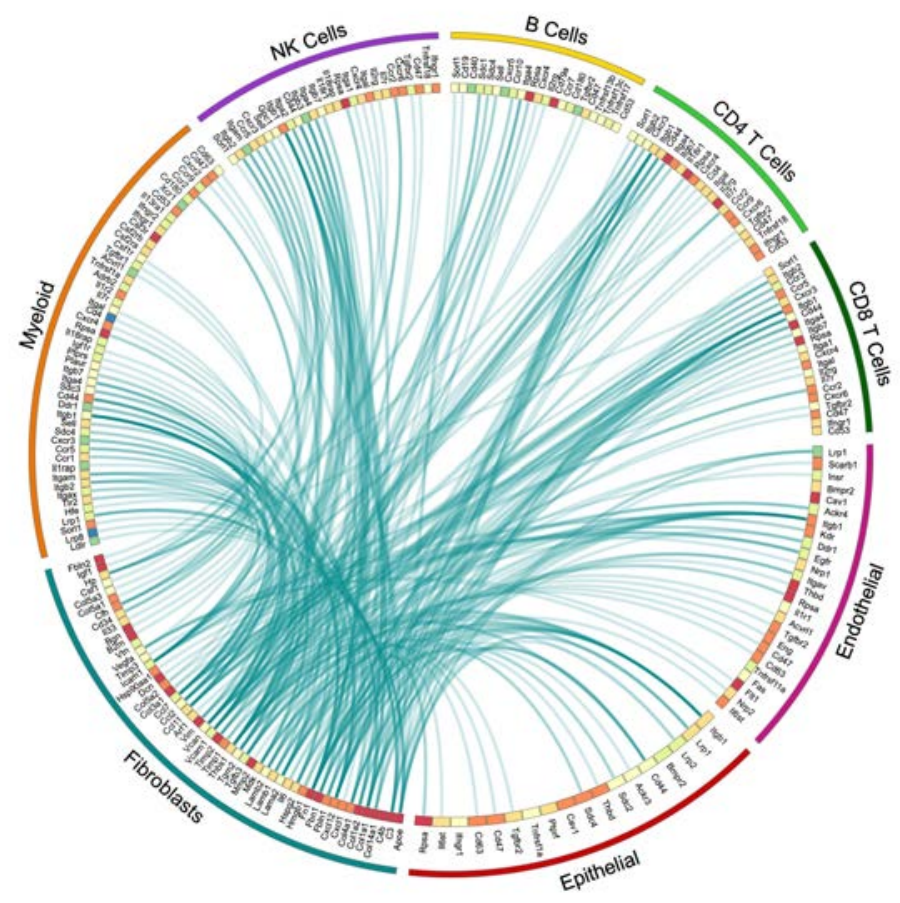

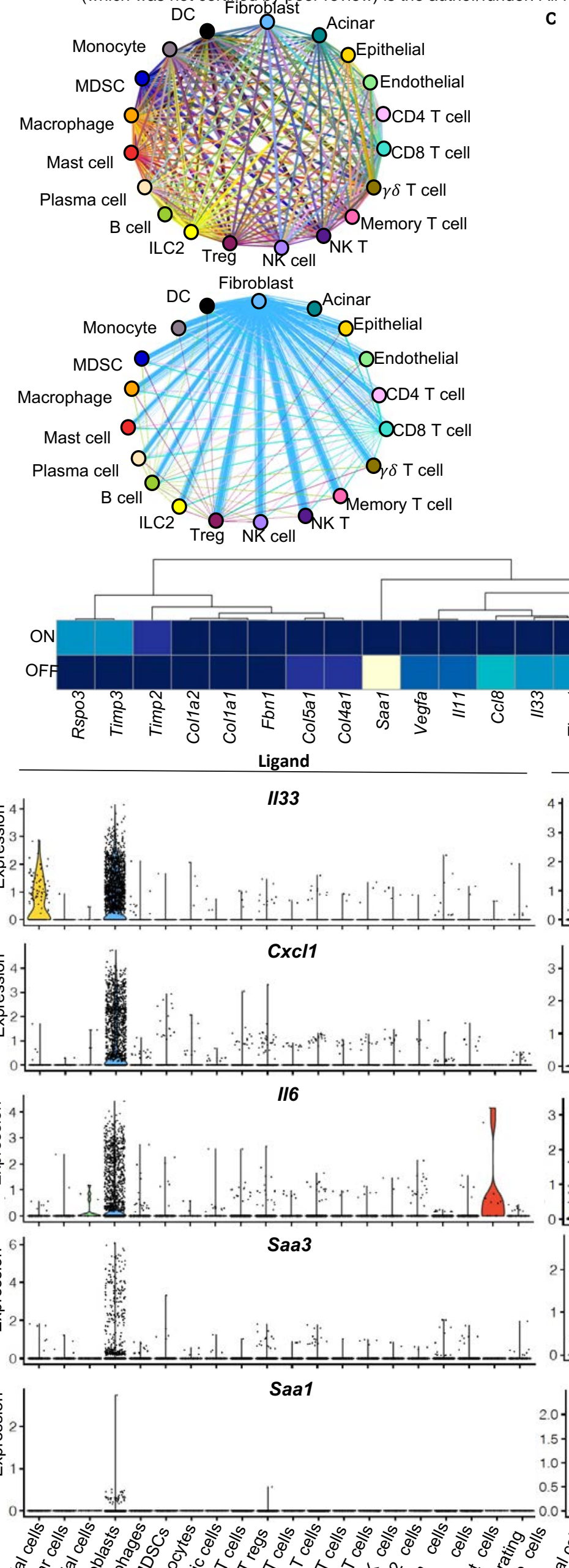

E
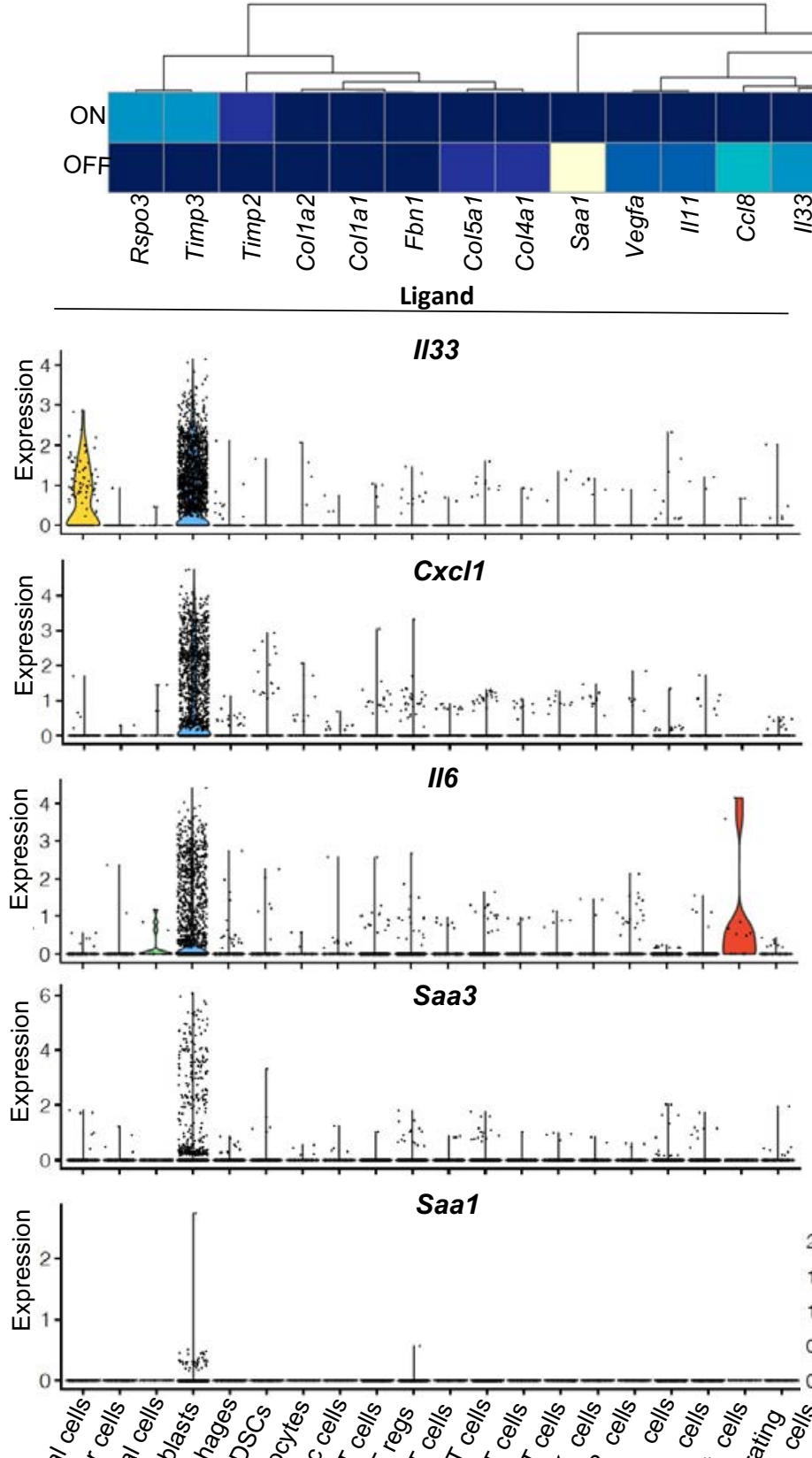

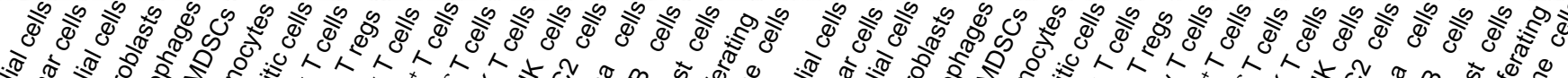

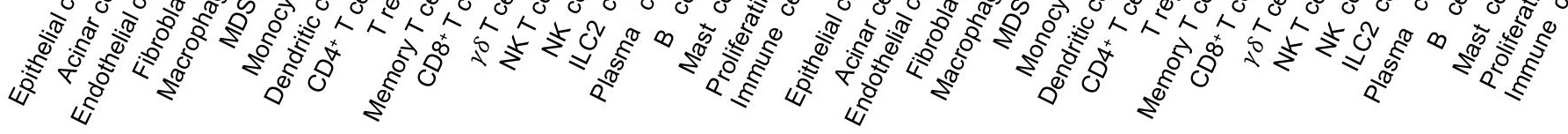


Figure 4. Fibroblasts are important mediators of the immune infiltration.

A, Interactome analysis showing all predicted ligand-receptor interactions between different cell populations identified in iKras* pancreatic single-cell RNA sequencing analysis. Each line represents a ligand-receptor pair, color-coded by the celltype expressing the ligand. B, Differential interactions from A positively regulated by oncogenic Kras (higher in $3 w$ ON compared to $3 \mathrm{~d}$ OFF) (adjusted $\mathrm{p}$ value $<0.05$ ). C, Circos plot showing average expression of fibroblast ligands connected to their predicted receptors on various cell populations as measured in the pancreatic single-cell RNA sequencing analysis. Ligands shown are from $\mathbf{B}$ (adjusted $p$ value $<0.05$ ). D, Heatmap showing averaged single-cell RNA sequencing expression data (relative to the highest expressor) for genes in fibroblasts from a curated list of immunomodulatory factors. E, Violin plots showing expression of II33, Cxcl1, II6, Saa3 and Saa1 and their respective receptors II1rl1, Cxcr2, I/6ra, P2rx7 and Scarb1 across all identified cell populations in both Kras* ON and OFF samples combined. See also Figure S4 
A

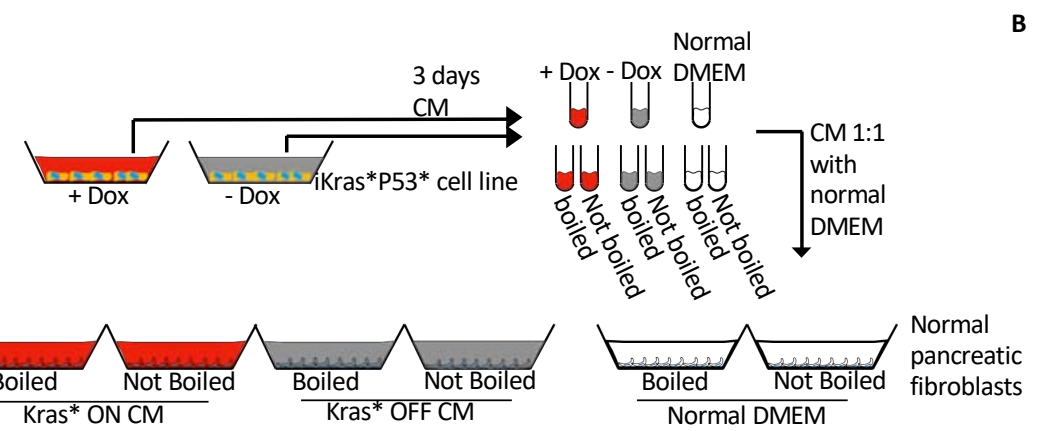

C

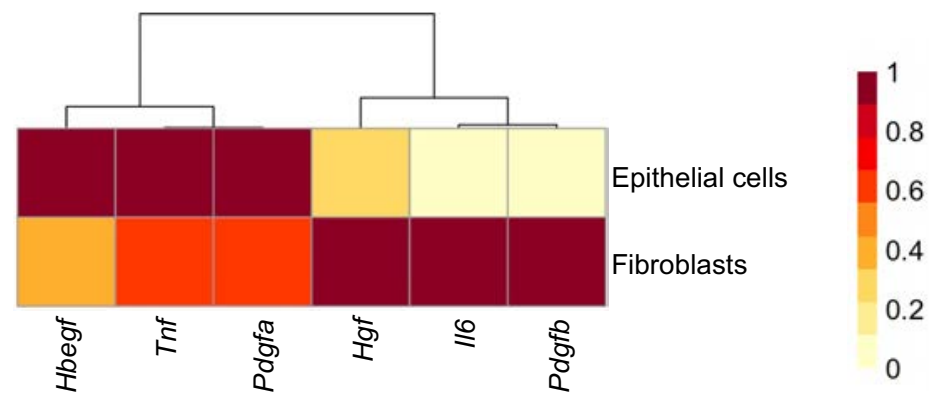

B

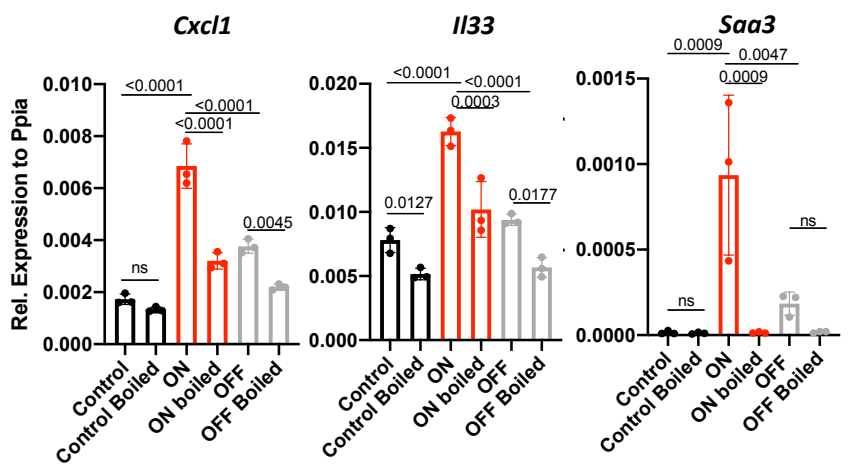

D
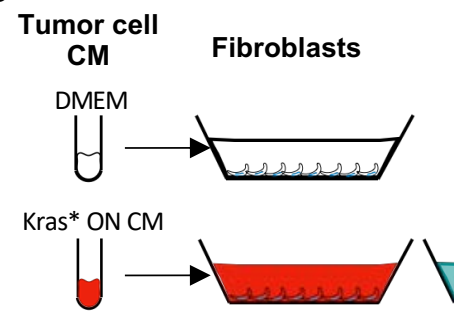

Kras* OFF CM

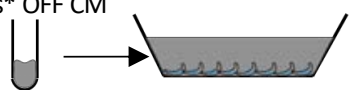

CD1WT:

E
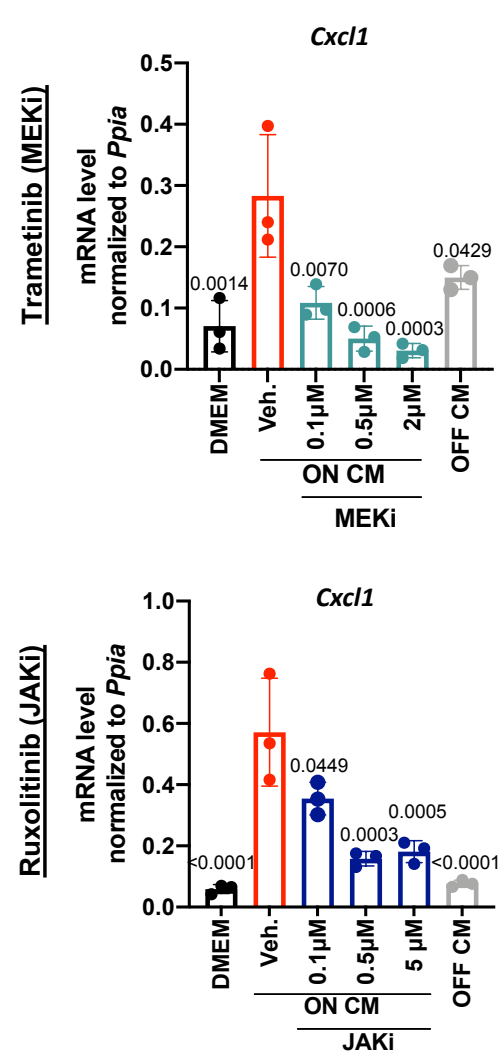
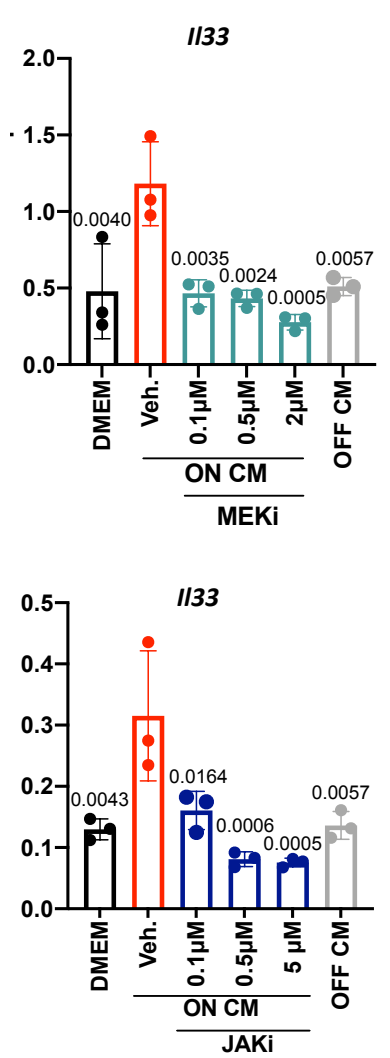
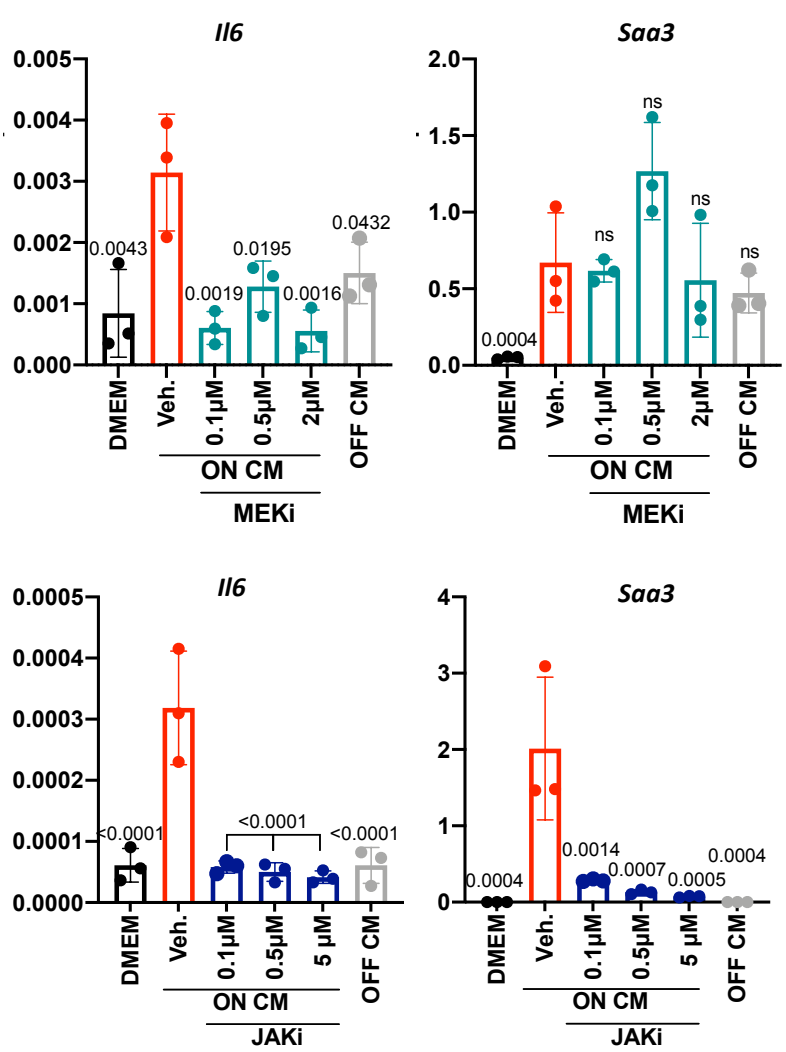

(which was not certified by peer review) is the author/funder. All rights reserved. No reuse allowed without permission.

Figure 5. Fibroblasts are reprogrammed through Kras*-induced activation of the MAPK and JAK/STAT signaling pathways.

A, Experimental design. Conditioned media (CM) was collected from iKras* cancer cells cultured with Doxycycline (+DOX) to activate Kras* expression (Kras* ON) or without Doxycycline (-DOX, Kras* OFF). The media samples were then boiled, to denature protein factors, or left intact, and used to culture pancreatic fibroblasts. DMEM was used as control. B, qRT-PCR for Cxcl1, I/33 and Saa3 expression in fibroblasts (CD1WT) that were cultured with CM either from Kras* ON, Kras* OFF or DMEM, either boiled or not boiled. Gene expression was normalized to Ppia. Data was shown as mean \pm SD. N=3 per group. The statistic differences were determined by multiple comparison ANOVA. C, Heatmap showing averaged single-cell RNA sequencing expression data (relative to the highest expressor) for genes encoding for ligands that are secreted by fibroblasts and epithelial cells. D, Experimental design. Fibroblasts were exposed to iKras*P53* tumor cell CM either from Kras* ON, Kras* OFF or DMEM. Fibroblasts cultured with Kras* ON CM media were treated with either a MEK inhibitor (Trametinib), a JAK/STAT 2/3 inhibitor (Ruxolitinib) or vehicle. E, qRT-PCR results for Cxc/1, I/33, I/6 and Saa3 expression in fibroblasts (CD1WT) treated with $\mathrm{CM}$ as described in panel D. Data shown as mean $\pm \mathrm{SD}$. $\mathrm{N}=3$ per group. The statistical differences were determined by multiple comparison ANOVA. See also Figure S5 


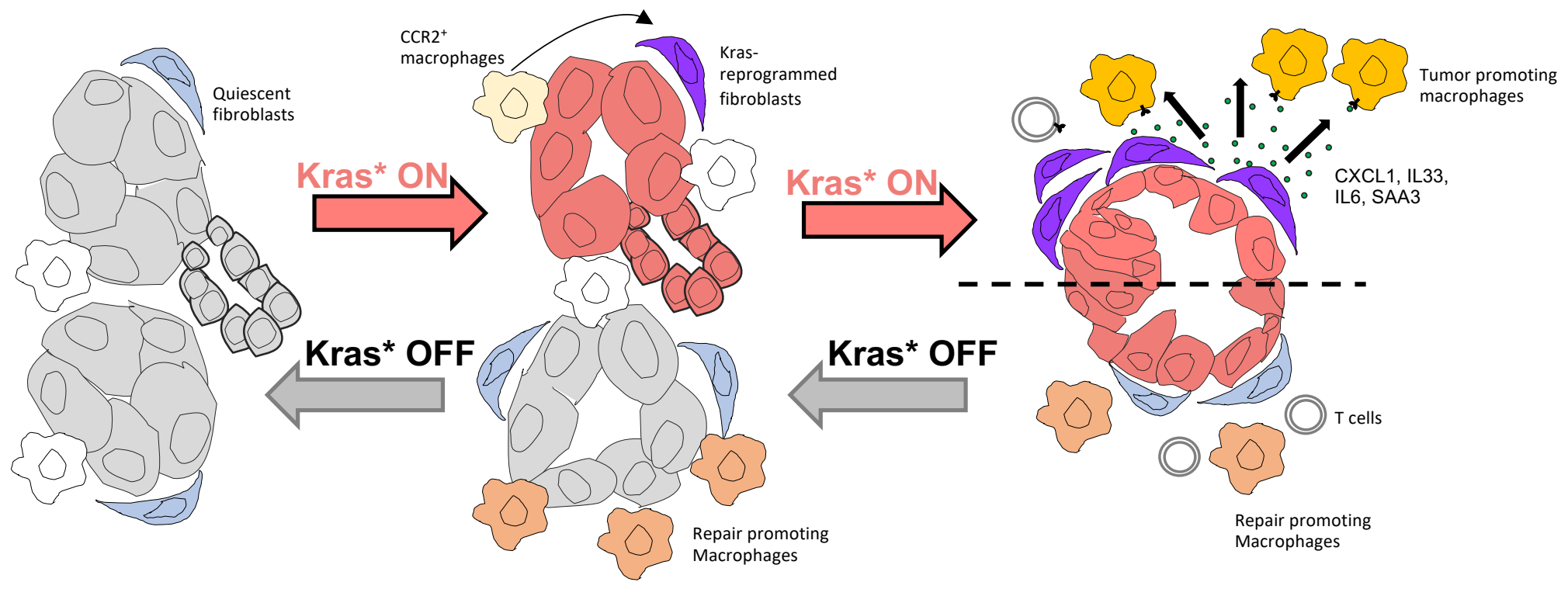

Figure 6. Working model. Upon Kras* expression, $\mathrm{CCR}^{+}$monocyte-derived macrophages infiltrate the pancreas, to complement preexisting resident macrophages. Infiltrating CCR2 ${ }^{+}$macrophages are required to activate pancreatic fibroblasts. MAPK and JAK/STAT signaling are activated in fibroblasts at the PanIN stage, and induce expression of $\mathrm{Cxc} / 1,1 / 33,1 / 6$, and Saa3. These inflammatory molecules have receptors on immune cells, many of which are myeloid cells. In turn, the JAK/STAT3 pathway becomes activated in macrophages resulting in a tumor-promoting phenotype. Upon Kras* inactivation in the epithelial cells, inflammatory molecule expression is downregulated in fibroblasts, and macrophages are reprogrammed to a tissue repair phenotype that promotes the re-differentiation of acinar cells. 